\title{
Imidacloprid Impairs Performance on a Model Flower Handling Task in Bumblebees (Bombus impatiens)
}

Jordan D. Phelps, The University of Western Ontario

Supervisor: Sherry, David F., The University of Western Ontario

A thesis submitted in partial fulfillment of the requirements for the Master of Science degree in Psychology

(C) Jordan D. Phelps 2018

Follow this and additional works at: https://ir.lib.uwo.ca/etd

Part of the Other Psychology Commons

\section{Recommended Citation}

Phelps, Jordan D., "Imidacloprid Impairs Performance on a Model Flower Handling Task in Bumblebees (Bombus impatiens)" (2018). Electronic Thesis and Dissertation Repository. 5479.

https://ir.lib.uwo.ca/etd/5479

This Dissertation/Thesis is brought to you for free and open access by Scholarship@Western. It has been accepted for inclusion in Electronic Thesis and Dissertation Repository by an authorized administrator of Scholarship@Western. For more information, please contact wlswadmin@uwo.ca. 


\begin{abstract}
Bumblebees exposed to neonicotinoid pesticides collect less pollen on foraging trips. Exposed bumblebees are also slower to learn to handle flowers, which may account for reduced pollen collection. It is unclear, however, why neonicotinoid exposure slows learning to handle flowers. I investigated the effect of imidacloprid, a neonicotinoid pesticide, on bumblebee motor learning using a lab model of flower handling. Bumblebees learned to invert inside a narrow tube and lift a petal-shaped barrier to reach a reward chamber. Imidacloprid-exposed bumblebees showed a dose-dependent delay to solve the task, which resulted from reduced switching between behavioural strategies and a subsequent delay in use of the successful strategy. This effect was consistent in colonies exposed at 10 but not $2.6 \mathrm{ppb}$, suggesting a variable effect on individuals at lower doses. These results help to explain why exposed bumblebees are slow to learn to handle flowers and collect less pollen on foraging trips.
\end{abstract}




\section{Keywords}

bumblebees, imidacloprid, neonicotinoid, learning, behaviour, cognition, pesticide, foraging, flower handling 


\section{Co-Authorship Statement}

The work described in this thesis was completed under the supervision of Dr. David Sherry and in collaboration with Dr. Caroline Strang. Dr. Sherry contributed to experimental design, edited the manuscript and provided funding for the experiment. Dr. Strang contributed to experimental design and developed the flower handling model. This work will be submitted for publication with Dr. Sherry and Dr. Strang as co-authors. 


\section{Acknowledgements}

First, to Dr. David Sherry, thank you for being an outstanding advisor. Your guidance throughout my undergraduate and masters work has shaped me as a scientist, writer and speaker. I feel well-equipped to move on to my $\mathrm{PhD}$ because of the skills and confidence you have helped me to develop. Thank you as well for giving me the freedom to pursue a research project that interested me deeply as an undergraduate. It was through this opportunity that I began to truly love science. Your calm, supportive presence makes you a wonderful advisor and person.

To Dr. Caroline Strang (who, as many of her students have pointed out, deserved the title long before she acquired the relevant piece of paper), thank you for welcoming me into the lab as a volunteer, introducing me to the wonderful world of bumblebee cognition and teaching me all I needed to know to work with bumblebees in the lab. The time you spent teaching me how to tag bees, design experiments, score videos, analyze data and generally not die while working with hundreds of bees was critical to my success. It is difficult for me to express how grateful I am, just as it will be for the graduate students you supervise in the future. You are a brilliant scientist, a selfless mentor and a kind friend.

To the members of my advisory committee, Dr. Bill Roberts and Dr. Graham Thompson, thank you for your helpful suggestions. Thank you as well to Dr. Roberts for spontaneous SSC elevator chats about my project and animal cognition, and for being there during fire drills through rain and snow to share my frustration about fire-drill-induced increases in inter-trial interval. "I've got a pigeon in a box upstairs" is probably the best and least likely utterance of annoyance in response to a fire drill.

To friends and colleagues in the Sherry and Roberts labs, thank you for all of your support and helpful feedback. Your comments always greatly improved my presentations. To Hayden MacDonald and Gordon Lo in particular, thank you both for your positive presence on the sparsely populated eighth floor of the SSC - you both made it a great environment to work in. I would like to thank my volunteer, Shayla Jackson, for her assistance and company testing bees and scoring videos, which can often be a lonely endeavour. Thank you as well to Felicity Muth for helpful correspondence, and for kindly offering a place to stay during the BOMBUSS conference where I learned a great deal about bumblebees.

To Jackie Lebenzon, thank you for being there every step of the way. You made long, coffee-fueled writing nights enjoyable and encouraged me to take much-needed excursions. 
Thank you as well for your PowerPoint wizardry - figure 2.1 would not exist without your help. To my parents, Kristie Partridge and Gary Phelps, thank you for your constant support, encouragement and interest in my research. You have been critical to my success as a student. To my grandparents, thank you for your support and interest in my research, but also for the many bee-related newspaper articles you have thoughtfully clipped out to show me over the years. It means a lot.

Last but not least, I would like to thank the bees. Thanks, of course, to the bumblebees that provided me with data, but also thanks to the wild bees, without which my diet would be dismally bland, and my garden much less alive. 


\section{Table of Contents}

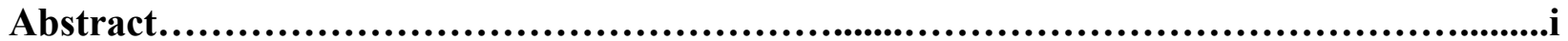

Keywords.................................................................................ii

Co-Authorship Statement...................................................................ii

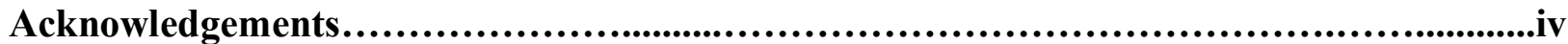

Table of Contents.........................................................................vi

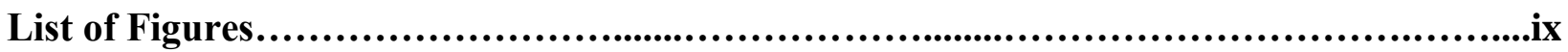

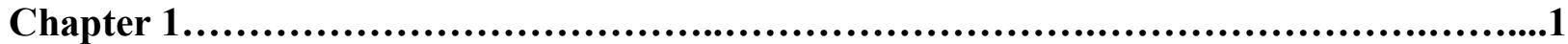

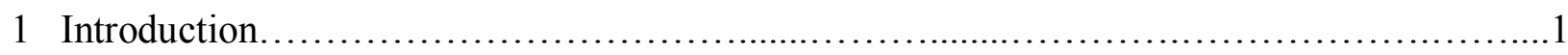

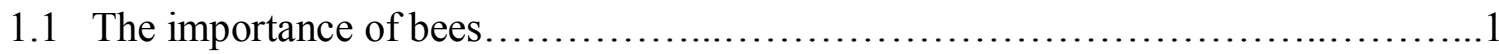

1.2 Bee declines and underlying causes...........................................

1.3 Neonicotinoids: usage, mode of action, and routes of exposure to bees.............4

1.4 The case of bumblebees.................................................

1.4.1 The bumblebee lifecycle: periods of vulnerability to neonicotinoids........6

1.4.2 What does it take to forage successfully?.............................

1.4.3 Neonicotinoids and bumblebees: what is known? ........................8

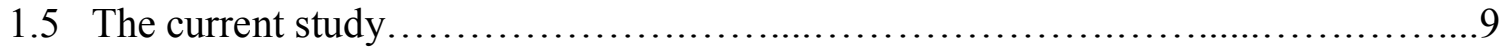

Chapter 2............................................................................11

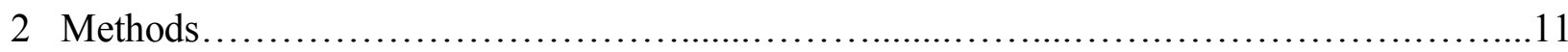

2.1 Subjects.................................................................. 11

2.2 Testing apparatus........................................................... 11

2.3 Preparation and provision of sucrose solution.............................. 12

2.4 Behavioural task............................................................ 12

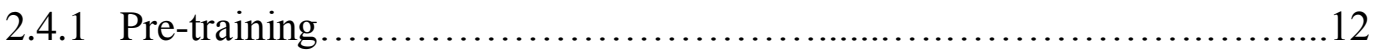

2.4.2 Testing procedure................................................ 13

2.4 .3 Video analysis.................................................... 14

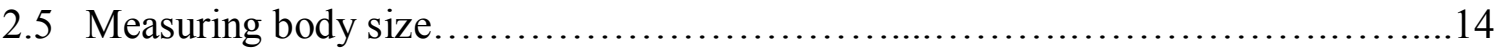

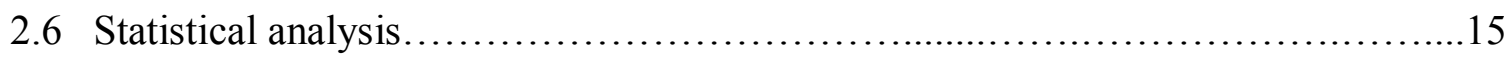

Chapter 3.......................................................................................... 18

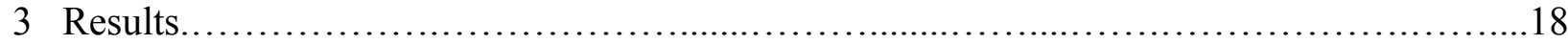

3.1 Effectiveness of inverting to lift and pushing............................... 18 
3.2 Latency to remove the rewarded barrier........................................... 18

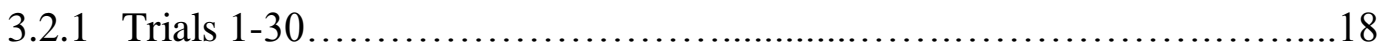

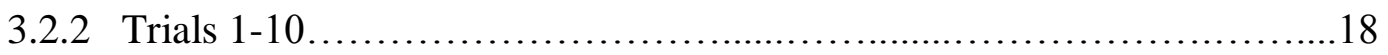

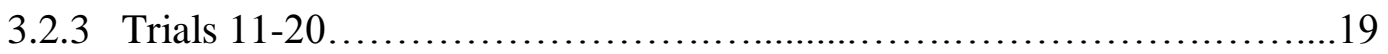

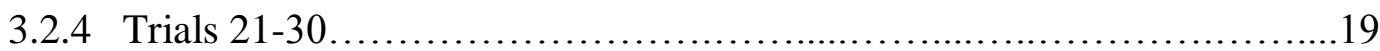

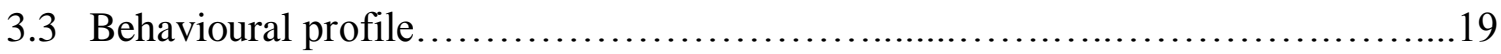

3.4 Proportion of time inverting to lift the rewarded barrier.............................20

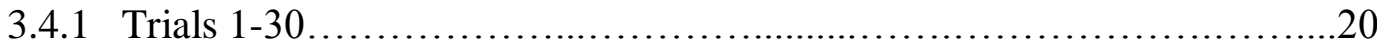

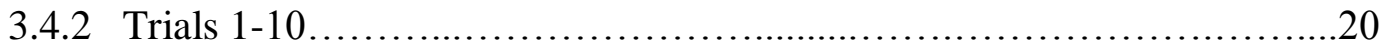

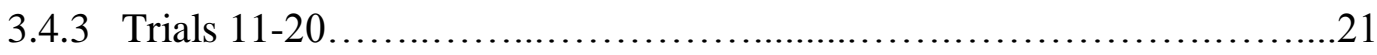

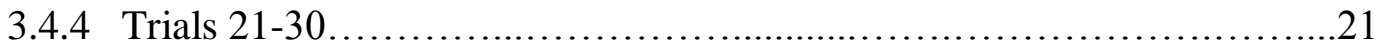

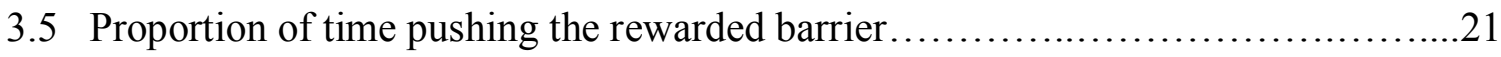

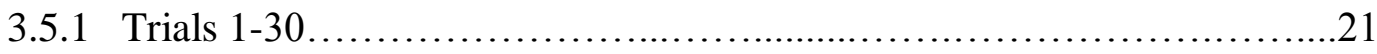

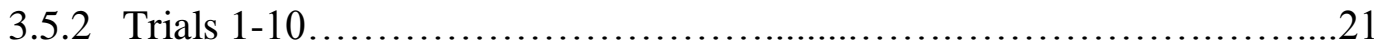

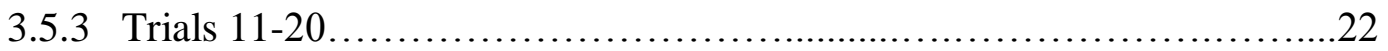

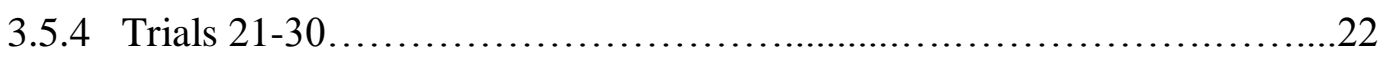

3.6 Proportion of time inverting to lift the non-rewarded barrier..........................22

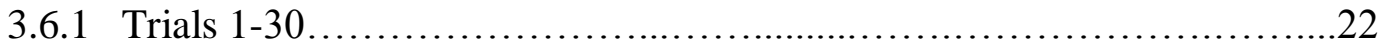

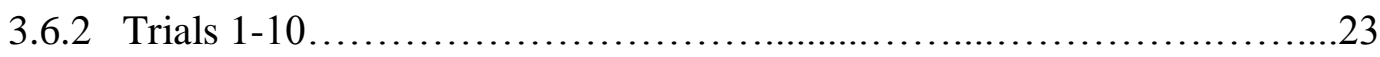

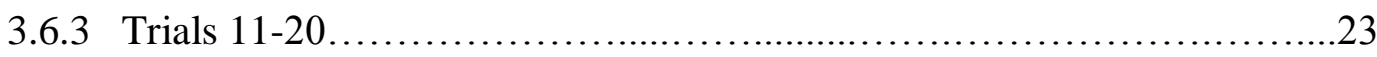

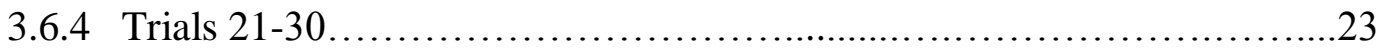

3.7 Proportion of time pushing the non-rewarded barrier............................23

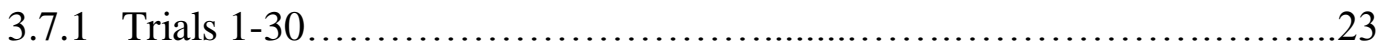

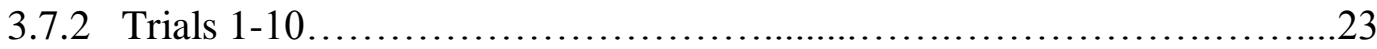

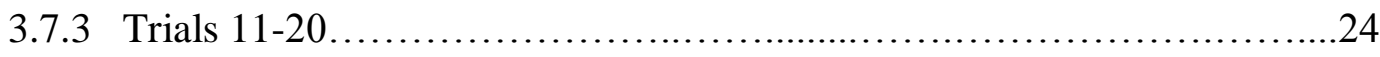

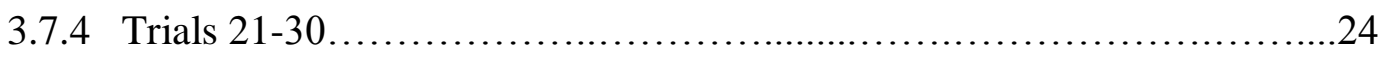

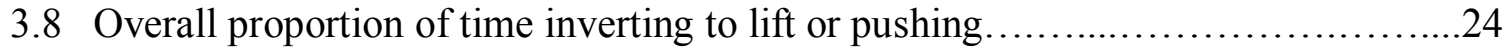

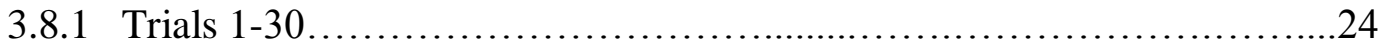

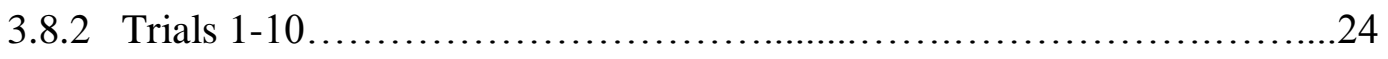

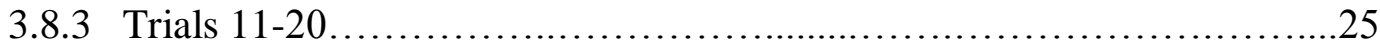

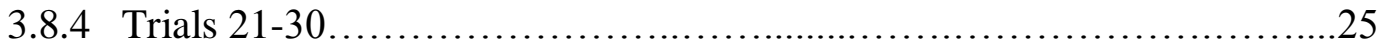




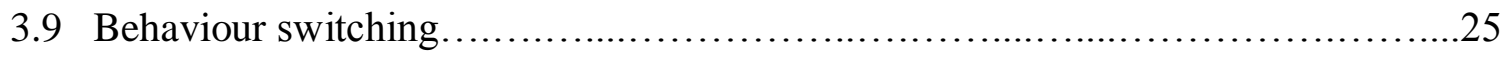

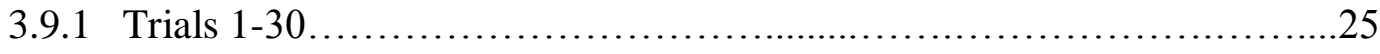

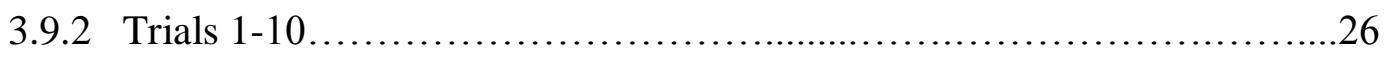

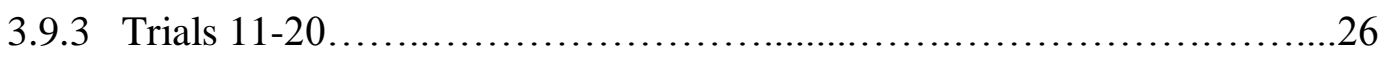

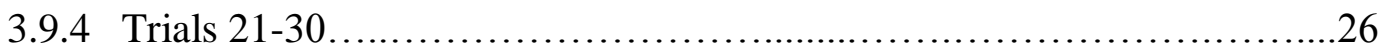

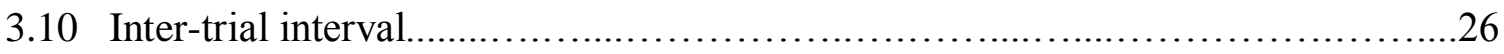

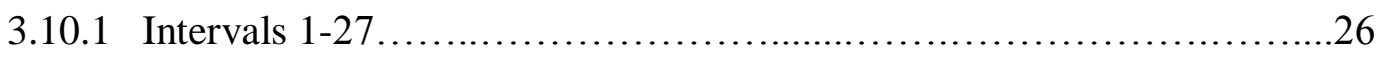

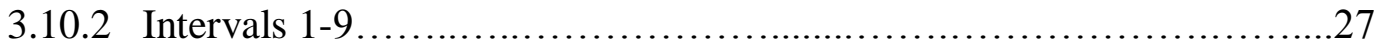

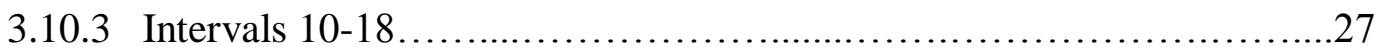

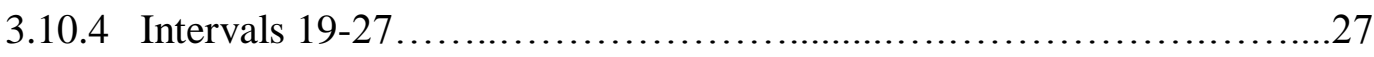

3.10.5 Inter-trial interval and latency to remove the rewarded barrier...........27

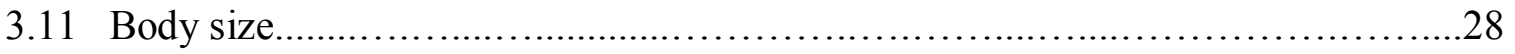

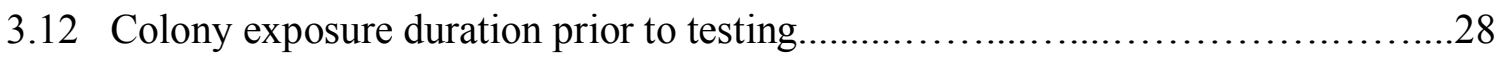

3.13 Colony differences in latency to remove the rewarded barrier....................28

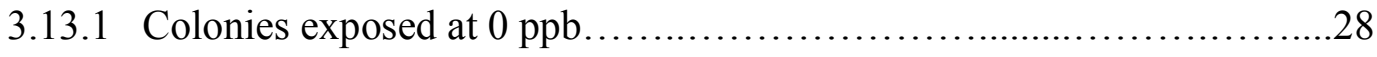

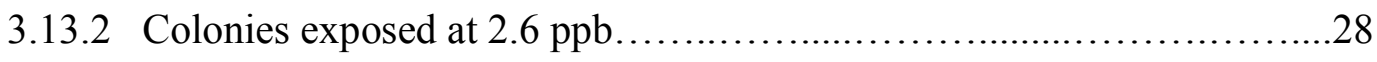

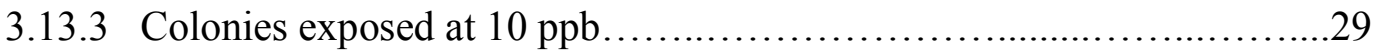

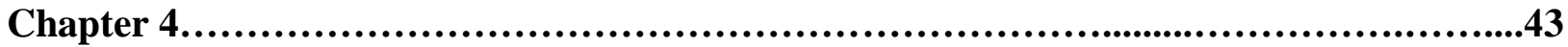

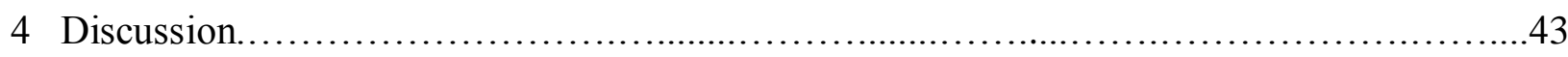

References....................................................................................49

Curriculum Vitae..............................................................................64 


\section{List of Figures}

Figure 2.1. The testing apparatus consisted of a $2 \mathrm{~cm}$ diameter Perspex ${ }^{\circledR}$ tube connected to the flight cage at one end and to a $6.4 \mathrm{~cm}^{3}$ Perspex ${ }^{\circledR}$ reward chamber on the other. During trials, the plastic (rewarded) barrier was placed in the slot closest to the reward chamber and the metal (non-rewarded) barrier was placed in the slot closest to the flight cage. Bumblebees learned to invert and lift the plastic barrier to receive a sucrose reward. Microcentrifuge tube lids in the reward chamber contained $40 \%$ sucrose solution

Figure 3.1. Latency to remove the rewarded barrier. Imidacloprid-exposed bumblebees showed a dose-dependent increase in latency to remove the rewarded barrier, but all bees performed similarly by trial 30 . Vertical bars represent overnight retention intervals between days one and two and between days two and three. Bumblebees were slower to remove the rewarded barrier following the second overnight retention interval, but not the first. Error bars equal \pm 1 standard

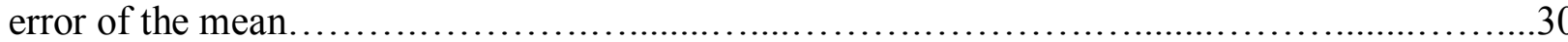

Figure 3.2. Proportion of time engaging in four behaviours: inverting to lift the rewarded and non-rewarded barriers and pushing the rewarded and non-rewarded barriers. Unexposed bumblebees (a) and bumblebees exposed at $2.6 \mathrm{ppb}$ (b) behaved similarly, but those exposed at $10 \mathrm{ppb}$ (c) took longer to shift to the strategy of inverting to lift the plastic barrier. Bumblebees in all conditions rapidly abandoned the non-rewarded barrier. Error bars equal \pm 1 standard error

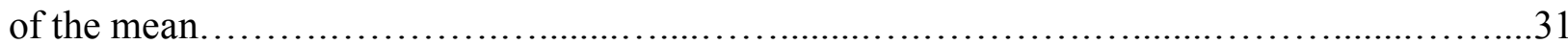

Figure 3.3. Proportion of time inverting to lift the rewarded barrier. Bumblebees in all conditions spent a greater proportion of time inverting to lift the rewarded barrier across trials but this increase was slowest for bumblebees exposed at $10 \mathrm{ppb}$. Bumblebees showed reductions in inverting to lift the rewarded barrier after both overnight retention intervals. Error bars equal \pm 1

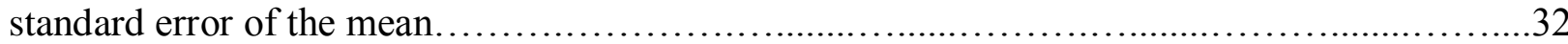

Figure 3.4. Proportion of time pushing the rewarded barrier. Bumblebees increased in proportion of time pushing the rewarded barrier to trial six and decreased thereafter. Bumblebees exposed at 
$10 \mathrm{ppb}$ experienced the greatest increase up to trial six and decreased at the slowest rate. Error

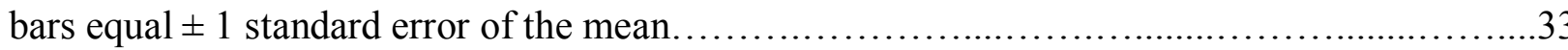

Figure 3.5. Proportion of time inverting to lift the non-rewarded barrier. Bumblebees in all conditions decreased in proportion of time inverting to lift the non-rewarded barrier on day one and rarely inverted to lift it thereafter. Errors bars equal \pm 1 standard error of the mean.

Figure 3.6. Proportion of time pushing the non-rewarded barrier. Bumblebees in all conditions decreased in proportion of time pushing the non-rewarded barrier on day one and rarely pushed it

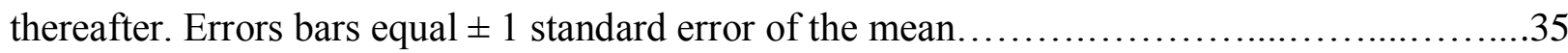

Figure 3.7. Overall proportion of time inverting to lift or pushing either barrier. Bumblebees increased overall in proportion of time inverting to lift or pushing on day one and remained stable thereafter, with bumblebees exposed at $10 \mathrm{ppb}$ spending a slightly greater proportion of time inverting to lift or pushing. Error bars equal \pm 1 standard error of the mean...................36

Figure 3.8. Number of behaviour switches per second. Unexposed bumblebees switched between behaviours at a higher rate than did bumblebees exposed at 2.6 or $10 \mathrm{ppb}$ during early trials. Errors bars equal \pm 1 standard error of the mean.

Figure 3.9. Inter-trial interval in minutes. Bumblebees exposed at $10 \mathrm{ppb}$ took longer between trials during day one than did unexposed bumblebees and those exposed at $2.6 \mathrm{ppb}$. Error bars

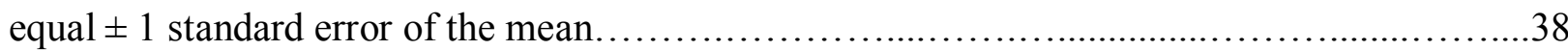

Figure 3.10. Composite latency as a function of average within-day inter-trial interval duration. Bumblebees with longer within-day inter-trial intervals were slower to remove the rewarded barrier overall $(\mathrm{r}=.44)$. This relationship was significant for bumblebees exposed at $2.6 \mathrm{ppb}(\mathrm{r}=$ $.56)$, close to significant for unexposed bumblebees $(\mathrm{r}=.39)$ and non-significant for those exposed at $10 \mathrm{ppb}(\mathrm{r}=.28)$ 
Figure 3.11. Composite latency as a function of thorax width. There was no relationship between thorax width and composite latency $(r=-.05)$. Bumblebee thorax width did not vary by condition.

Figure 3.12. Composite latency as a function of the day of colony exposure on which individual bumblebees began testing. There was no relationship between composite latency and colony exposure duration prior to testing $(\mathrm{r}=-.09)$. Colony exposure duration prior to testing did not vary by condition.

Figure 3.13. Latency to remove the rewarded barrier. Bumblebees from (a) unexposed colonies one $(\mathrm{n}=7)$, two $(\mathrm{n}=9)$ and three $(\mathrm{n}=9)$ performed similarly. Bumblebees from (b) $2.6 \mathrm{ppb}$ imidacloprid-exposed colony two $(n=9)$ were slower to remove the rewarded barrier than those from colony one $(n=6)$ and three $(n=10)$. Bumblebees from $(\mathbf{c}) 10 \mathrm{ppb}$ imidacloprid-exposed colonies one $(n=8)$, two $(n=8)$ and three $(n=9)$ performed similarly. Error bars equal \pm 1 standard error of the mean. 


\section{Chapter 1}

\section{Introduction}

\subsection{The importance of bees}

Bees diverged from the apoid wasps over 100 million years ago in the mid-Cretaceous period at roughly the same time as the early angiosperm radiation (Danforth et al., 2013; Doyle, 2012). In the millions of years that followed, bees and flowering plants became intimately linked (Grimaldi, 1999; Hu et al., 2008; Willmer, 2011). Flowering plants evolved to offer nectar and pollen rewards to bees and other pollinators in exchange for their unwitting pollination services. Bees evolved to exploit these nectar and pollen rewards, which not only made them more efficient foragers, but more efficient pollinators from the plant perspective. Foods from flowering plants are central to the human diet (Şerban et al., 2008), and the age-old reliance of many flowering plant species on animal pollinators remains paramount to our success in food production. There are many animal pollinators (Rader et al., 2016). No pollinator group is more important to the success of human agriculture and wild plant populations, however, than bees (Calderone, 2012; Delaplane \& Mayer, 2000; Forup et al., 2008; Klein et al., 2007; Mallinger \& Gratton, 2015).

It is difficult to overstate the ecological and economic importance of animal pollination. Ollerton and colleagues (2011) estimated that $87.5 \%$ of flowering plants are animal-pollinated. In addition, the extent to which animal pollination benefits agriculture is substantial. Thirty-nine of the fifty-seven most commonly grown crops for human consumption either depend on or benefit from animal pollination and account for $35 \%$ of agricultural food production (Klein et al., 2007). These crops include blueberry, apple, almond, avocado, tomato, coffee, cocoa, and many others that make our diets diverse and enjoyable. Global pollination services - the vast majority of which are performed by bees - have been valued at approximately 217 billion USD per year (Gallai et al., 2009; Rader et al., 2016).

If asked to think of bees, most people would think first of the European honey bee (Apis mellifera). This is no coincidence. Humans have exploited honey bees for honey and beeswax since at least the Neolithic period (Dams \& Dams, 1977; Roffet-Salque et al., 2015) and have long marveled at their complex social organization (Seeley, 2010; von Frisch, 1967). It is the 
contribution of honey bees to crop pollination, however, that makes them invaluable. By sheer number, the ease with which colonies can be managed, and the variety of plants they are able to pollinate, the honey bee is the single greatest contributor to overall crop pollination (Calderone, 2012; Gallai et al., 2009; Klein et al., 2007; Moritz et al., 2010; Rader et al., 2016). They are also major pollinators of wild plants (Hung et al., 2018).

While the honey bee is clearly important, its success too often casts a shadow over the importance of the other 16,000 or more bee pollinators (Batra, 1995; Michener, 2007; Smith et al., 2016). Other managed bee species, including bumblebees (Bombus spp.), mason bees (Osmia spp.), the alfalfa leafcutter bee (Megachile rotundata), and the alkali bee (Nomia melanderi) are viable alternatives and often more effective pollinators than honey bees (Horth \& Campbell, 2018; Richards, 1993, 2016; Vergara \& Fonseca-Buendía, 2012; Westerkamp, 1991). For example, bumblebees are used regularly in greenhouses to pollinate the tomato plant (Solanum lycopersicum) which requires floral sonication (the extraction of pollen from flowers by buzzing) for effective pollination; bumblebees, but not honey bees, are capable of sonication (Morgan et al., 2016; Rick, 1950). Perhaps most important, however, is the diverse population of wild bees that play an enormous role as pollinators behind the scenes and often outperform managed bees overall (Garibaldi et al., 2013; Rader et al., 2016; Winfree et al., 2008).

The human need for crop pollination is clear. Managed honey bees are not increasing along with the demand for pollination required to feed the growing human population (Aizen \& Harder, 2009). Therefore, to maximize pollination, a flourishing, diverse population of wild and managed pollinators is required. It is thus concerning that wild and managed bee populations have been undergoing widespread declines (Cameron et al., 2011; Goulson et al., 2008; National Research Council, 2007; Potts et al., 2010a; Potts et al., 2010b).

\subsection{Bee declines and underlying causes}

Evidence for bee declines is widespread but generally differs by species and location. While managed honey bees have increased globally over the past half-century, they have not increased at the same rate as demand for pollination, and several important regional declines have been observed (Aizen \& Harder, 2009). For example, managed honey bee colonies have declined sharply in the USA (by 59\% between 1947 and 2005; National Research Council, 2007) and central Europe (by 25\% between 1985 and 2005; Potts et al., 2010b). While much less is 
known about wild honey bees, limited evidence suggests that they are almost non-existent in areas with managed colonies (De la Rúa et al., 2009; Jaffé et al., 2010).

Among wild bees, bumblebee (Bombus spp.) populations have been best documented, and it is clear that widespread declines in abundance and diversity have occurred (Potts et al., 2010a). At least 50\% of British bumblebee species are in decline, and these tend to be specialists with narrow foraging ranges (Biesmeijer et al., 2006; Goulson et al., 2008; Williams \& Osborne, 2009). Similar declines have been documented across western and central Europe by Kosior and colleagues (2007). Only $20 \%$ of bumblebee species were considered not threatened in all 11 countries studied, while $80 \%$ were threatened in at least one. In North America, reports of decline have come from Ontario and across the United States (Colla \& Packer, 2008; Grixti et al., 2009; Jacobson et al., 2018). Importantly, the relative abundance of four once common species has decreased by up to $96 \%$ (Cameron et al., 2011). Unfortunately, much less is known about the status of bee populations other than Apis and Bombus (Brown \& Paxton, 2009), though a recent review suggests that flying insects have decreased overall during the past few decades (Hallman et al., 2017).

What is driving these declines? Several anthropogenic factors have been identified and are likely interacting to stress bee populations (Goulson et al., 2008; Potts et al., 2010a). Landuse change is a primary cause; agricultural intensification and urban development have reduced and fragmented the natural habitats bees rely on for forage and nesting (Kremen et al., 2007; Ricketts et al., 2008; Winfree et al., 2009), and resultant genetic isolation increases the risk of inbreeding (Zayed, 2009). In addition, warming associated with climate change is compressing the natural range limits of bumblebees by pushing their southern range limits northward (Kerr et al., 2015). The introduction of invasive species, such as the Varroa destructor mite and Nosema spp., has severely impacted wild and managed bees (Dainat et al., 2012; Otti \& Schmid-Hempel, 2008), and it is increasingly clear that the use of commercially bred bumblebee colonies in greenhouses is facilitating pathogen spread to wild bee populations (Graystock et al., 2014; Mallinger et al., 2017; Otterstatter \& Thomson, 2008). Agrochemicals affect bees both directly and indirectly, with pesticides affecting bee health via consumption and topical application (Godfray et al., 2016; Nuyttens et al., 2013; Wood \& Goulson, 2017) and herbicides affecting bee nutrition by reducing forage (Holzschuh et al., 2008). It has also been shown that pesticides 
can exacerbate the effect of pathogens on bee populations (Doublet et al., 2015; Pettis et al., 2012; Prisco et al., 2013).

Clearly many interacting stressors underlie bee declines. One pesticide class, however, has been singled out as an important culprit: neonicotinoids (Goulson, 2013). The European Food Safety Authority (EFSA) was commissioned to produce risk assessments for the three most widely used neonicotinoids - imidacloprid, thiamethoxam and clothianidin - and on the basis of these reports, a temporary moratorium on the three compounds was implemented in the EU in 2013 (EFSA, 2013a, b, c). Ontario subsequently regulated neonicotinoid usage in 2015 with the goal to reduce neonicotinoid-treated seed applications by $80 \%$ before 2017 (Ministry of the Environment and Climate Change, 2015). Neonicotinoid pesticides and their risk to bees will be discussed in the following section.

\subsection{Neonicotinoids: usage, mode of action, and routes of exposure to bees}

Neonicotinoid pesticides were introduced to the market in the early 1990s and have since become the fastest growing pesticide class, overtaking organophosphates, methylcarbamates and pyrethroids (Jeschke et al., 2011; Wood \& Goulson, 2017). Several neonicotinoid compounds exist - of which the most commonly used are imidacloprid, thiamethoxam and clothianidin - and all of these function by mimicking acetylcholine and binding to nicotinoic acetylcholine receptors (nAChRs) in the insect nervous system (Jeschke et al., 2011; Matsuda et al., 2001). High-affinity binding of neonicotinoids to insect $\mathrm{nAChRs}$ can cause rapid overstimulation and block normal acetylcholine function; this results in paralysis and death at sufficiently high concentrations, and a suite of cognitive and motor deficits at sub-lethal concentrations (Godfray et al., 2015; Scott-Dupree et al., 2009; Sgolastra et al., 2016; Tomizawa \& Casida, 2005).

A major reason for the market success of neonicotinoids is that they can be applied to crops easily as a seed coating (Elbert et al., 2008; Jeschke et al., 2011). Neonicotinoids are water-soluble and systemic; thus, they can be taken up by the plant via roots and integrated into the tissues of the growing plant (Sur \& Stork, 2003). In this way, neonicotinoids provide plants protection from herbivorous insects for months with no need for repeated applications (Jeschke et al., 2011). Reduced application frequency does minimize the risk of topical pesticide exposure across the growing season. Two concerning routes of neonicotinoid exposure to bees, however, have been identified. 
One form of exposure is via dust emitted by pneumatic drilling machines used during the sowing of neonicotinoid-coated seeds (Nuyttens et al., 2013). Drilling machines often abrade the seed coatings and emit toxic particulates which are then encountered by foraging bees. Reports of mass honey bee die-offs via contaminated dust in the early 2000s stimulated a great deal of concern and risk assessment (Bartolotti et al., 2009; Chauzat et al., 2010; Nuyttens et al., 2013).

Early research suggested that the risk posed by contaminated dust was low (Schnier et al., 2003), but several follow-up studies contradicted this, showing that contaminated dust contains neonicotinoid concentrations lethal to honey bees and bumblebees (Girolami et al., 2012; Girolami et al., 2013; Godfray et al., 2015; Scott-Dupree et al., 2009). While exposure via dust is a concern, exposure risk is relatively brief and air deflector use during sowing can reduce toxic particulate emissions by up to $95 \%$ (Manzone et al., 2016).

The second, more insidious form of neonicotinoid exposure is via the consumption of nectar and pollen of treated plants. While concentrations in nectar and pollen vary widely based on several factors (including neonicotinoid compound, treatment method, plant species and soil type), they typically range from $<1$ to $10 \mathrm{ppb}$ (parts per billion) and are higher in pollen than in nectar (Blacquière et al., 2012; Bonmatin et al., 2015; Godfray et al., 2015; Wood \& Goulson, 2017). These concentrations occur in both treated crops and nearby wildflowers; since crops treated via seed coating only take up about $5 \%$ of the active ingredient (Sur \& Stork, 2013), the remainder is left to persist in soil and water where it is commonly taken up by non-target plants (Botías et al., 2015; David et al., 2016; Long \& Krupke, 2016; Morrissey et al., 2015; Radonlinksi et al., 2016). Neonicotinoids are clearly prevalent in nectar and pollen, but these levels are well below lethal. The honey bee 48-h LD50 following oral exposure for imidacloprid, clothianidin and thiamethoxam ranges from 3.7 to $5 \mathrm{ng} / \mathrm{bee}$ (>160 ppb), and for bumblebees appears higher despite variation (Godfray et al., 2015; Sgolastra et al., 2016). Evidence points instead to sub-lethal effects of neonicotinoids that impair bee functioning on an individual and colony level. Sub-lethal exposure can negatively affect reproductive success (Laycock et al., 2012; Rundlöf et al., 2015; Whitehorn et al., 2012; Woodcock et al., 2017), foraging success (Feltham et al., 2014; Gill et al., 2012; Gill \& Raine, 2014; Stanley et al., 2016), navigation (Henry et al., 2012; Matsumoto, 2013), learning and memory (Decourtye et al., 2004a; Decourtye et al., 2004b; Han et al., 2010; Phelps et al., 2018; Samuelson et al., 2016; Stanley et al., 2015a; Williamson and Wright 2013), motor function (Williamson et al., 2014), 
thermoregulation (Tosi et al., 2016), and even the quality of pollination provided by bees (Stanley et al., 2015b). This accumulation of sub-lethal effects represents a clear threat to bee populations and global pollination services.

Much of this work, however, has focused on the honey bee (Cresswell et al., 2011;

Lundin et al., 2015), and it has become increasingly clear that extrapolating these results to other, often vastly different, bee species is inappropriate (Piiroinen \& Goulson, 2016; Rundlöf et al., 2015; Sgolastra et al., 2016; Stoner, 2016). The present study investigates sub-lethal effects of a neonicotinoid on bumblebees, and therefore the remainder of the introduction will focus on what is known about the genus Bombus exclusively.

\subsection{The case of bumblebees}

Bumblebees are clearly among the most important wild pollinators in the temperate zone (Corbet et al., 1991; Goulson, 2009; Plowright \& Laverty, 1987). The large body, thick hair and thermogenic ability of bumblebees makes them highly cold-tolerant, and able to forage across a wider range of climatic conditions than honey bees (e.g. at low temperatures and during rainfall; Corbet et al., 1993; Heinrich, 2004). Bumblebees are primitively eusocial, with three castes (queens, workers and drones), workers that can perform a variety of tasks in the colony (e.g. foraging and tending to larvae) and an annual life cycle (Goulson, 2009). It is crucial to understand this life cycle, as well as the behaviour and cognition of bumblebee foraging, in order to understand how neonicotinoids may affect bumblebees at the individual and group level.

\subsubsection{The bumblebee life cycle: periods of vulnerability to neonicotinoids}

Queen bumblebees emerge from diapause between late winter and early spring each year to search for a nesting site. Once a site is chosen, the queen must forage for pollen to provision the nest with. She then lays her first batch of 8-16 eggs within the pollen and begins incubation (Goulson, 2009). This stage of the life cycle is incredibly precarious; if the queen fails to locate a high quality nest site, collect resources or lay and incubate her first batch of eggs, the colony is likely to collapse. This is the first stage at which neonicotinoids likely affect bumblebees, by reducing the ability of queens to initiate a colony.

It takes approximately 4-5 weeks for the brood to become adult workers (Alford, 1975). At this point, the workers take over foraging duties, the queen continues to lay eggs, and if all 
goes well, the colony grows rapidly and switches from producing workers to reproductives (i.e. queens and drones) that will mate and initiate colonies the following year (Goulson et al., 2002; Müller \& Schmid-Hempel, 1992). Unfortunately, all rarely goes well. While over $50 \%$ of colonies produce drones, fewer than $25 \%$ grow large enough to produce queens, which are far more resource-costly (Cumber, 1953; Müller \& Schmid-Hempel, 1992; Owen et al., 1980). Of these queen-producing colonies, it is typical for the very largest to produce the vast majority of queens (>60 queens) and the smallest to produce few (Müller \& Schmid-Hempel, 1992). The fate of the following year's bumblebee population therefore hinges on a tiny fraction of colonies that grow large enough to produce queens. This strategy is vulnerable to any factors that reduce colony growth, which is heavily reliant on worker bees collecting sufficient resources (i.e. pollen and nectar) to feed the queen and developing offspring (Duchateau \& Velthuis, 1988; Vogt et al., 1998). This period of colony growth is the second stage at which neonicotinoids are likely to affect bumblebee colonies, by affecting the foraging success of workers.

What does it take for foraging bumblebees to be successful? The following section will review key behavioural and cognitive aspects of bumblebee foraging that can be affected by neonicotinoid exposure.

\subsubsection{What does it take to forage successfully?}

Bumblebees feed exlcusively on pollen and nectar. Pollen is the main protein source for bumblebees, and critical to the development of offspring, while nectar provides the energy they require to function. Bumblebees are generalist foragers, meaning that they are able to forage upon a wide array of flowers (Goulson, 2009; Waser et al., 1996). Despite this, individuals tend to develop preferences for rewarding flower types by associating rewards with floral features such as colour, scent and shape (Chittka, 1998; Dukas \& Real, 1991; Goulson, 2009; Kulahci et al., 2008). With many flower types to choose from, it is crucial that bumblebees rapidly learn which are rewarding and preferentially forage on them. Indeed, colonies with faster-learning workers tend to collect resources at a higher rate (Raine \& Chittka, 2008; but see Evans et al., 2017).

It is not enough, however, for bumblebees to learn which flowers are rewarding - they must also be able to extract pollen and nectar from them. Flowers are morphologically diverse; while pollen and nectar are exposed and easily accessible in some, they are concealed in others, 
hidden in atypical locations or behind petals (Laverty, 1980; Ronse De Craene, 2010). To efficiently collect pollen and nectar, bumblebees must learn how to handle flowers of varying morphological complexity (Heinrich, 1976, 1979; Laverty, 1980; Laverty \& Plowright, 1988). The importance of learning in flower handling has been well-documented. Naïve bumblebees make frequent errors when handling novel flowers, but with experience these errors dissapear almost completely and the speed with which bumblebees extract resources increases manyfold (Heinrich, 1979; Laverty, 1980). This learning process is brief when flowers are morphologically simple, but can take much longer for complex flowers, especially when petal manipulation is necessary (Heinrich, 1979; Laverty, 1980, 1994a). There appears, however, to be a strong innate component to flower handling as well. For example, bumblebees are commonly directed to land on particular regions of flowers via visual nectar guides, and probe in central locations (Laverty, 1980; Lunau, 1991). Recent work suggests that bumblebees handling novel flowers may employ an innate behavioural repertoire and fine-tune performance through associative learning, with successful motor patterns being reinforced by floral rewards (Strang, 2018).

\subsubsection{Neonicotinoids and bumblebees: what is known?}

While most risk assessments of neonicotinoids to bees have focused on the honey bee, bumblebees are the second most commonly studied (Lundin et al., 2015). The current state of knowledge will be summarised with focus on two highly vulnerable life cycle stages: colony initiation and colony growth.

As discussed, colony initiation by queens is a highly demanding and precarious stage of the bumblebee life cycle. Studies have indicated that sub-lethal neonicotinoid exposure can delay and reduce both colony initiation and brood emergence (Baron et al., 2017a; Wu-Smart \& Spivak, 2018). Even a slow start could mean the difference between a colony producing queens or not. In addition, Baron and colleagues (2017b) found that exposed queens developed smaller oocytes, which could negatively affect egg-laying. These studies are informative, but more work must be done to determine neonicotinoid effects on queens during this stage - particularly on how exposure affects foraging and nutrition (Stoner, 2016).

A greater volume of work has focused on the stage of colony growth. Importantly, many studies have shown reduced reproductive success in exposed colonies, with exposed colonies growing to a lesser degree and often producing fewer queens (Laycock et al., 2012; Rundlöf et 
al., 2015; Whitehorn et al., 2012; Woodcock et al., 2017; but see Stanley \& Raine, 2017). How are neonicotinoids limiting colony growth? A possible explanation is that exposed bumblebees are collecting fewer resources, which would limit nutrient availability for developing offspring. This explanation has been well-supported, with several studies documenting pollen foraging deficits in exposed bumblebees (Feltham et al., 2014; Gill et al., 2012; Gill \& Raine, 2014; Stanley et al., 2016; Whitehorn et al., 2017). Pollen is the key bumblebee protein resource, and crucial for the nutrition of developing bumblebees.

How might neonicotinoid exposure reduce the foraging success of bumblebee workers? The answer to this question is less clear. Past work has shown neonicotinoid-induced delays in associative learning using colours and scents as reward cues (Phelps et al., 2018; Stanley et al., 2015a), however, the evidence appears mixed (Piiroinen \& Goulson, 2016, Piiroinen et al., 2016). In one study it was found that neonicotinoids induced spatial memory deficits, which may have implications for homing and avoidance of depleted flowers (Samuelson et al., 2016).

Flower handling, however, which is a crucial component of bumblebee foraging, has not been given much attention. Reduced learning and execution of sonication behaviour has been well-documented in exposed bumblebees (Switzer \& Combes, 2016; Whitehorn et al., 2017), and recent work by Stanley and Raine (2016) has shown that exposed bumblebees take more trials to efficiently obtain pollen from novel, morphologically complex flowers (Lotus corniculatus and Trifolium repens). However, the precise mechanism underlying this learning delay in exposed bumblebees remains unclear, and more detailed behavioural analysis is required.

\subsection{The current study}

Strong evidence suggests that neonicotinoid exposure reduces bumblebee reproductive success by limiting foraging performance. In previous work, I showed that neonicotinoid exposure slows learning about which food sources contain the highest concentrations of sucrose (Phelps et al., 2018). Exposed bumblebees are also slower to learn how to handle morphologically complex flowers but the cause remains unclear. The goal of this thesis was twofold: (1) to assess the effects of neonicotinoid exposure on bumblebee motor learning, and (2) to isolate the cause of delays in motor learning for flower handling. A lab model of flower handling developed by Strang (2018) was used to accomplish these goals. Using this model it was possible to assess the performance of bumblebees exposed to imidacloprid, a common 
neonicotinoid, on a motor task analogous to petal manipulation in flower handling. Bumblebees were required to manipulate a petal-shaped barrier in order to receive a sucrose reward. As with actual flowers, this task had only one effective solution. Testing occurred across three consecutive days for a total of 30 trials (10 trials per day) to assess between- and within-day learning. Importantly, while past research has identified deficits in motor learning, behavioural output was quantified here with the precision necessary to explain deficits mechanistically.

Based on previous research (Stanley \& Raine, 2016), I hypothesized that imidacloprid exposure delays motor learning in bumblebees. Specifically, I predicted that bumblebees exposed to imidacloprid would take longer to solve the motor task across trials, and that this effect would be dose-dependent. It is plausible that neonicotinoid-induced overstimulation and blockage of $\mathrm{nAChRs}$ could result in learning and motor decicits that could together disrupt the process of motor learning. I predicted that imidacloprid-exposed bumblebees would be slower to acquire the motor strategy necessary to solve the task (i.e. they would spend a lower proportion of time engaging in the successful strategy across trials), which could explain a delay to solve the task in exposed bumblebees. 


\section{Chapter 2}

\section{Methods}

\subsection{Subjects}

Nine queenright Bombus impatiens colonies of approximately 50 to 100 bumblebees were obtained from a commercial supplier (Biobest Canada Ltd., Leamington, ON). Colonies were randomly assigned to one of three conditions: chronic imidacloprid exposure at $0,2.6$ or 10 $\mathrm{ppb}$. Three colonies were therefore assigned to each condition. Data were collected from a total of 75 bumblebees: 25 from unexposed colonies, 25 from colonies exposed at $2.6 \mathrm{ppb}$, and 25 from colonies exposed at $10 \mathrm{ppb}$. Data were collected from a similar number of bumblebees in each colony $(M=8.33, S D=1.22)$. Colonies were kept on a 12-h light: 12 -h dark schedule (onset $0700 \mathrm{~h}$ ) and housed in hive boxes (30.5(l) x 24(w) x 20(h) cm) connected to flight cages (104(l) x 64(w) x 92(h) cm) by a $2 \mathrm{~cm}$ diameter Perspex ${ }^{\circledR}$ tube. Control and exposed colonies were housed in separate rooms to prevent contamination of control bumblebees with imidacloprid. Flight cages contained four artificial flower patches with four artificial flowers each. Patches were rectangular sections of Styrofoam $(20 \times 32 \mathrm{~cm})$ and artificial flowers were clear 1.7-ml microcentrifuge tubes (Axygen Inc., Union City, CA) with $5 \mathrm{~cm}$ wide clear, plastic corollas. Bumblebees foraged ad libitum for $20 \%$ sucrose solution from artificial flower patches. Sucrose solution was replenished using 5-ml syringes (VWR International Co.). The floor of the flight cage was covered in disposable surface protector (Whatman Benchkote ${ }^{\circledR}$ ). Pollen was

given ad libitum to colonies directly in the hive box. Bumblebees were given unique markings on the thorax with Posca paint markers (Mitsubishi Pencil Co.) for identification.

\subsection{Testing apparatus}

The testing apparatus consisted of a Perspex ${ }^{\circledR}$ reward chamber $\left(6.4 \mathrm{~cm}^{3}\right)$ connected to the flight cage by a $2 \mathrm{~cm}$ diameter Perspex ${ }^{\circledR}$ tube (Fig. 2.1). The apparatus was elevated $35 \mathrm{~cm}$ above the floor of the flight cage. An artificial flower was placed at the tube entrance and three 1.7-ml microcentrifuge tube lids were placed in the reward chamber; each of these could be baited with $40 \%$ sucrose solution. The reward chamber had a hinged lid which was securely fastened by a magnetic closure. Six $3 \mathrm{~mm}$ diameter holes were drilled into the reward chamber 
for ventilation. There were two $1 \mathrm{~cm}$ deep slots in the tube $6.5 \mathrm{~cm}$ apart. Plastic and metal barriers were placed through these slots during testing. Each barrier $(25 \times 13 \mathrm{~mm})$ was rectangular but rounded at the bottom. The bottom of each barrier fit the shape of the tube, but not perfectly; there was slight gap beneath each barrier through which a bumblebee could insert its forelegs to lift it. The plastic (rewarded) barrier was light enough for bumblebees to lift and blocked access to the reward chamber. The metal (non-rewarded) barrier was too heavy to be lifted and blocked access to the flight cage.

\subsection{Preparation and provision of sucrose solution}

Imidacloprid was obtained in dry powder form (Imidacloprid PESTANAL Fluka 37894, Sigma-Aldrich). Stock solutions of 1 ppm (part per million) imidacloprid were made by mixing 1 mg of imidacloprid in $1 \mathrm{~L}$ of distilled water using a vortex mixer. Fresh $300 \mathrm{~mL} 2.6$ and $10 \mathrm{ppb}$ imidacloprid sucrose solutions were created by further diluting stock solution in fresh 20 and $40 \%$ sucrose solutions. Undosed 20 and $40 \%$ sucrose solutions were also made in $300 \mathrm{~mL}$ batches. Sucrose concentration was verified using a refractometer. Solutions were stored away from sunlight in amber tinted glass bottles to prevent imidacloprid breakdown caused by UV light exposure (Soliman, 2012).

Three colonies were unexposed, three were chronically exposed to $2.6 \mathrm{ppb}$ imidacloprid, and three were chronically exposed to $10 \mathrm{ppb}$ imidacloprid. All sucrose solution collected by exposed colonies from artificial flowers and the reward chamber contained that colony's imidacloprid treatment. A chronic method of exposure was chosen to simulate the experience of bumblebees repeatedly foraging on imidacloprid-treated crops.

\subsection{Behavioural task}

\subsubsection{Pre-training}

Colonies were given a minimum of one week for imidacloprid exposure and habituation to foraging in the flight cage prior to testing. Bumblebees could move freely between the flight cage and the testing apparatus during this time. The artificial flower outside the tube and three microcentrifuge tube lids inside the apparatus were baited frequently, and bumblebees learned that these contained highly rewarding $40 \%$ sucrose solution. Only bumblebees foraging inside 
the apparatus were colour marked and tested.

\subsubsection{Testing procedure}

The learning task used in the present study was originally described by Strang (2018). Bumblebees were individually tested across three consecutive days for a total of 30 trials (10 trials per day). The apparatus was baited with $40 \%$ sucrose solution before testing to attract bumblebees and to ensure they developed an association between apparatus entry and reward. Prior to testing, all bumblebees were cleared from the apparatus and sucrose solution remaining in the artificial flower by the tube entrance was depleted.

During testing, a single marked bumblebee was allowed to enter the tube from the flight cage. The plastic barrier was inserted through the slot closest to the reward chamber and blocked the bumblebees' path to the reward. Once the bumblebee was inside, the metal barrier was placed through the slot behind it to prevent it from leaving and other bumblebees from entering. Trials were video recorded using a GoPro camera (GoPro® Hero3+ Silver camera, GoPro Inc., San Mateo, CA). The trial ended when the bumblebee removed the plastic barrier or when five minutes had passed. Bumblebees that were successful in removing the plastic barrier entered the reward chamber to consume $40 \%$ sucrose solution to satiation. If a bumblebee failed to remove the plastic barrier, the barrier was removed by the experimenter and the bumblebee was allowed to enter the reward chamber to consume $40 \%$ sucrose solution to satiation. Care was taken to ensure that unsuccessful bumblebees were not facing or interacting with the plastic barrier when it was removed. Once satiated, bumblebees were allowed to exit and return to the hive to deposit sucrose solution. Sucrose solution was replenished between trials. The next trial began when the marked bumblebee returned to the testing apparatus. Inter-trial interval (i.e. the time between the beginning of the previous trial and the beginning of the current trial) was recorded. Only a subset of worker bumblebees from each colony were tested. For inclusion, bumblebees had to return to the reward chamber frequently and participate in all 30 trials; it is thus likely that the most highly motivated bumblebees in each colony were selected. Because bumblebees self-initiated trials it was not possible to standardize inter-trial interval; for this reason, inter-trial intervals were highly variable. Data collection occurred for approximately 20 days for each colony, and this duration was similar across conditions. 


\subsubsection{Video analysis}

Videos were imported from the GoPro to an external hard drive (My Book 4TB, Western Digital Co.) after each testing session. A total of 2,250 videos were collected ( 75 bumblebees, 30 trials each). Latency to remove the plastic barrier and measures of behaviour were obtained by video analysis. Video analysis was conducted using the Noldus Observer XT software (Noldus Information Technology, Wageningen, Netherlands).

The onset of each trial was defined as a bumblebee crossing the slot through which the metal barrier was placed. At that point, video scoring began and continued until the plastic barrier was removed or until five minutes had passed. Latency to remove the plastic barrier was recorded in seconds for each trial. Bumblebees that failed to remove the plastic barrier were given a latency score of 300 seconds. Strang (2018) found that bumblebees attempted to remove the plastic barrier using two dominant strategies: inverting inside the tube to lift the barrier and pushing the barrier. These behaviours were thus selected for quantification. Inverting to lift was operationally defined as a bumblebee exerting pressure on the barrier with its head or forelegs while inverted at least $90^{\circ}$ to the left or right in the tube. Pushing was operationally defined as a bumblebee exerting pressure on the barrier with its head or forelegs while in an upright position (i.e. inverted less than $90^{\circ}$ ). Inverting to lift and pushing were quantified separately at each barrier. Four behaviours were quantified overall: (1) inverting to lift the rewarded (plastic) barrier, (2) pushing the rewarded (plastic) barrier, (3) inverting to lift the non-rewarded (metal) barrier and (4) pushing the non-rewarded (metal) barrier. The proportion of time bumblebees engaged in these behaviours was obtained by dividing the time spent engaging in each by latency to remove the rewarded barrier. The rate at which bumblebees switched between behaviours was obtained by dividing the number of switches by latency to remove the rewarded barrier.

\subsection{Measuring body size}

Head width (i.e. the distance between the lateral margin of the compound eyes) and thorax width (i.e. the distance between the lateral margin of the tegulae) were obtained from 60 of the bumblebees tested (19,21 and 20 from colonies exposed at 0,2.6 and $10 \mathrm{ppb}$ respectively) using a caliper (EZ-Cal IP54 Digital Caliper, iGaging Precision Instruments ®, San Clemente, California) with $0.01 \mathrm{~mm}$ precision. Measurements of head and thorax width were taken twice for each bumblebee on separate days. 


\subsection{Statistical analysis}

All analyses were conducted using SPSS (Version 24, IBM Corp.) with an alpha level of .05. Greenhouse-Geisser corrections were used when the sphericity assumption of analysis of variance (ANOVA) was violated. Post hoc tests were conducted using a Bonferroni correction.

Two Pearson correlations were used to analyze the relationship between latency to remove the rewarded barrier and proportion of time engaging in the two dominant behaviours (inverting to lift and pushing) at the rewarded barrier.

A repeated measures ANOVA was used to analyze (1) latency to remove the rewarded barrier, (2) behavioural profile (proportion of time engaged in each of the four behaviours), (3) proportion of time inverting to lift the rewarded barrier, (4) proportion of time pushing the rewarded barrier, (5) proportion of time inverting to lift the non-rewarded barrier, (6) proportion of time pushing the non-rewarded barrier, (7) proportion of time inverting to lift or pushing overall, (8) behaviour switching (number of times a bumblebee switched between behaviours divided by latency) and (9) inter-trial interval. Behavioural profile was analyzed once across all 30 trials to provide a general description of behavioural change between conditions. Because behaviour sometimes changed substantially across trials within a day, and because this pattern of change sometimes differed on successive days, other measures were analyzed using a series of four tests (trials 1-30, 1-10, 11-20 and 21-30) to examine within- and between-day differences.

For analyses of latency, proportion of time inverting to lift the rewarded and nonrewarded barrier, proportion of time pushing the rewarded and non-rewarded barrier, proportion of time inverting to lift or pushing overall and behaviour switching, a between-subjects factor of imidacloprid concentration $(0,2.6$ and $10 \mathrm{ppb})$ and a within-subjects factor of trial (1-30,1-10, 11-20 and 21-30 for each of four tests) were used.

For behavioural profile, a between-subjects factor of imidacloprid concentration $(0,2.6$ and $10 \mathrm{ppb}$ ), and within-subjects factors of behaviour (inverting to lift the rewarded barrier, pushing the rewarded barrier, inverting to lift the non-rewarded barrier, pushing the nonrewarded barrier) and trial (1-30) were used.

For inter-trial interval, a between-subjects factor of imidacloprid concentration $(0,2.6$ and $10 \mathrm{ppb}$ ) and within-subjects factor of interval were used. Four tests were performed: one for all 27 within-day inter-trial intervals, one for intervals 1-9 on the first day, one for intervals 1018 on the second day and one for intervals $19-27$ on the third day. Only the 27 within-day inter- 
trial intervals were included in this analysis; overnight inter-trial intervals were much longer and are not included. Four additional Pearson correlations were used to examine the relationship between mean within-day inter-trial interval and latency to remove the rewarded barrier in each condition and overall. A composite latency score for each bumblebee was generated for these analyses by summing latency across all 30 trials.

A Pearson correlation was used to examine the relationship between head and thorax measurements taken on days one and two. These were similar for head width $(\mathrm{r}=.98, p<.001)$ and thorax width $(\mathrm{r}=.99, p<.001)$, and thus measurements were combined for each as a mean value. A Pearson correlation was then used to examine the relationship between head and thorax width. These were also similar $(r=.94, p<.001)$, and therefore only thorax width was used subsequently. Four Pearson correlations were used to examine the relationship between thorax width and composite latency to remove the rewarded barrier for bumblebees in each condition and overall. A one-way ANOVA with the between-subjects factor of imidacloprid concentration $(0,2.6$ and $10 \mathrm{ppb})$ was used to confirm there were no differences in bumblebee thorax width between conditions.

A one-way ANOVA with the between-subjects factor of imidacloprid concentration ( 0 , 2.6 and $10 \mathrm{ppb}$ ) was used to confirm that there was no difference in colony exposure duration prior to testing (i.e. the number of days the colony was exposed prior to a bumblebee starting testing) for bumblebees between conditions. Four Pearson correlations were used to examine the relationship between exposure duration prior to testing and composite latency to remove the rewarded barrier for bumblebees in each condition and overall.

A repeated measures ANOVA was used to assess colony differences within each of the three imidacloprid exposure levels in latency to remove the rewarded barrier. A between-subjects factor of colony (1,2 and 3) and a within-subjects factor of trial (1-30) were used for each. 


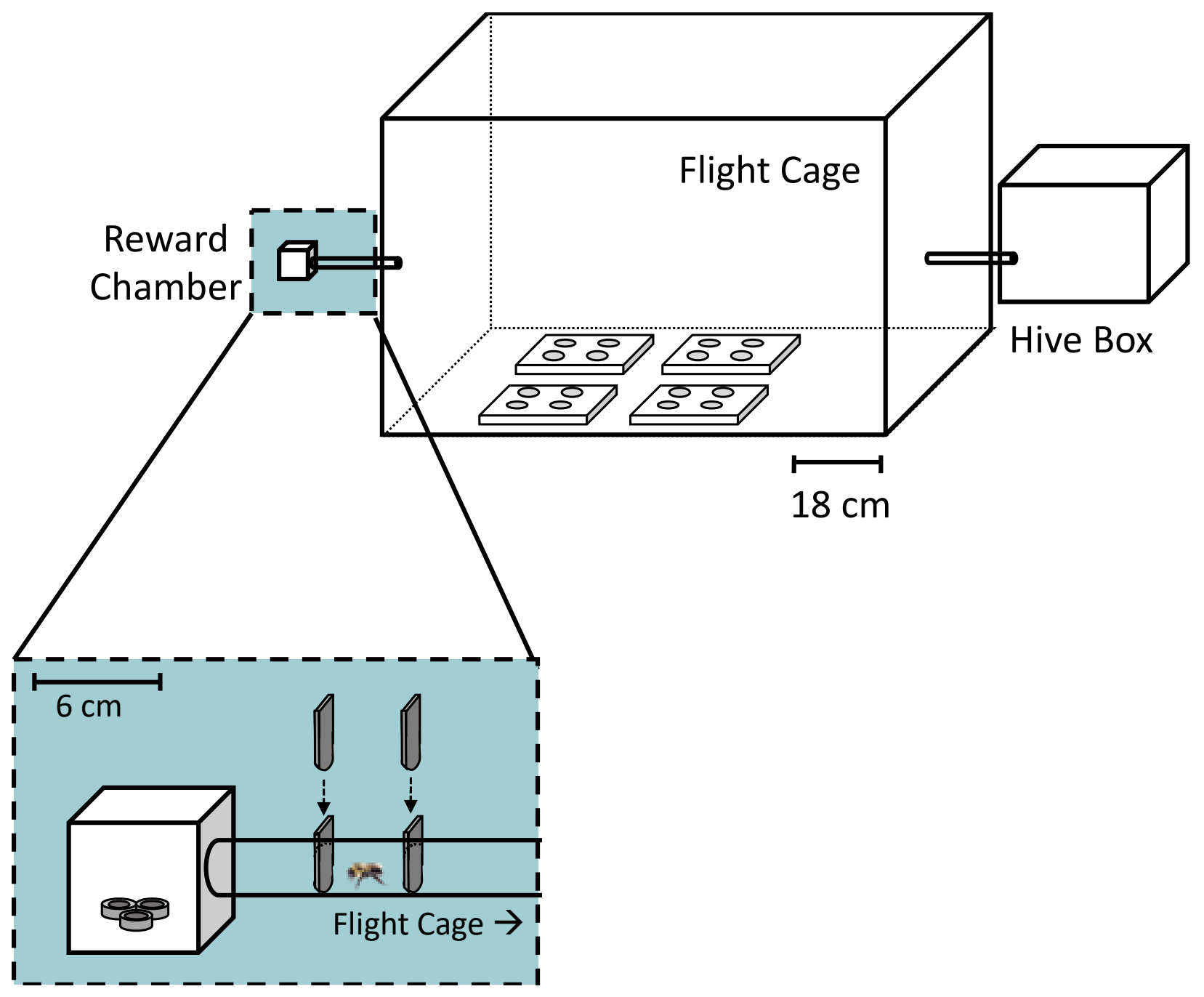

Figure 2.1. The testing apparatus consisted of a $2 \mathrm{~cm}$ diameter Perspex ${ }^{\circledR}$ tube connected to the flight cage at one end and to a $6.4 \mathrm{~cm}^{3}$ Perspex ${ }^{\circledR}$ reward chamber on the other. During trials, the plastic (rewarded) barrier was placed in the slot closest to the reward chamber and the metal (non-rewarded) barrier was placed in the slot closest to the flight cage. Bumblebees learned to invert and lift the plastic barrier to receive a sucrose reward. Microcentrifuge tube lids in the reward chamber contained $40 \%$ sucrose solution. 


\section{Chapter 3}

\section{Results}

\subsection{Effectiveness of inverting to lift and pushing}

There was a strong, negative correlation between proportion of time inverting to lift the rewarded barrier and latency to remove it $(\mathrm{r}=-.62, p<.001)$, and a positive correlation between proportion of time pushing the rewarded barrier and latency to remove it $(\mathrm{r}=.25, p<.001)$. Overall, bumblebees that maximized inverting to lift and minimized pushing were fastest to remove the rewarded barrier.

\subsection{Latency to remove the rewarded barrier}

\subsubsection{Trials 1-30}

There was a significant interaction between trial and imidacloprid concentration, $\left(F(22.23,800.22)=2.408, p<.001, \eta_{\mathrm{p}}^{2}=.06\right)$. Bumblebees from all groups became faster to remove the rewarded barrier across trials, but those exposed to imidacloprid improved more slowly and in a dose-dependent fashion (Fig. 3.1). A significant main effect of imidacloprid concentration was found $\left(F(2,72)=5.972, p=.004, \eta_{\mathrm{p}}{ }^{2}=.14\right)$. Post hoc tests revealed that unexposed bumblebees were faster to remove the rewarded barrier than those exposed at $10 \mathrm{ppb}$ $(p=.004)$, but the difference between unexposed bumblebees and those exposed at $2.6 \mathrm{ppb}$ fell

just short of significance $(p=.058)$ and bumblebees exposed at 2.6 and $10 \mathrm{ppb}$ did not differ $(p=$ 1.000). A significant main effect of trial was found $\left(F(11.11,800.22)=54.056, p<.001, \eta_{\mathrm{p}}{ }^{2}=\right.$ .43 ), indicating that bumblebees became faster to remove the rewarded barrier across trials. Post hoc tests revealed no difference in latency to remove the rewarded barrier between trial 10 and 11 (following overnight retention interval one), but bumblebees were slower to remove the rewarded barrier on trial 21 than on trial 20 (following overnight retention interval two; $p=$ $.033)$.

\subsubsection{Trials 1-10}

A significant main effect of imidacloprid concentration was found $(F(2,72)=14.072, p<$ $\left..001, \eta_{\mathrm{p}}{ }^{2}=.28\right)$. Post hoc tests revealed a dose-dependent effect of imidacloprid on latency to 
remove the rewarded barrier, such that unexposed bumblebees were faster than those exposed at $2.6(p=.035)$ and $10 \mathrm{ppb}(p<.001)$, and bumblebees exposed at $2.6 \mathrm{ppb}$ were faster than those exposed at $10 \mathrm{ppb}(p=.008)$. A significant main effect of trial was found $(F(6.14,442)=65.413$, $\left.p<.001, \eta_{\mathrm{p}}^{2}=.48\right)$, indicating that bumblebees became faster to remove the rewarded barrier across trials. There was no significant interaction between trial and imidacloprid concentration $\left(F(6.14,442)=0.997, p=.451, \eta_{\mathrm{p}}^{2}=.03\right)$.

\subsubsection{Trials 11-20}

A significant main effect of imidacloprid concentration was found $(F(2,72)=3.195, p=$ $.047, \eta_{\mathrm{p}}^{2}=.08$ ). Post hoc tests revealed no significant differences at $p<.05$, but the difference between unexposed bumblebees and those exposed at $10 \mathrm{ppb}$ was close to significant $(p=.058)$. A significant main effect of trial was found $\left(F(5.25,377.78)=5.591, p<.001, \eta_{\mathrm{p}}^{2}=.07\right)$, indicating that bumblebees became faster to remove the rewarded barrier across trials. There was no significant interaction between trial and imidacloprid concentration $(F(10.49,377.78)=$ $\left.1.101, p=.36, \eta_{\mathrm{p}}^{2}=.03\right)$.

\subsubsection{Trials 21-30}

A significant main effect of trial was found $\left(F(4.35,313.09)=5.569, p<.001, \eta_{\mathrm{p}}{ }^{2}=.07\right)$, indicating that bumblebees became faster to remove the rewarded barrier across trials. There was no significant main effect of imidacloprid concentration $\left(F(2,72)=1.329, p=.271, \eta_{\mathrm{p}}{ }^{2}=.04\right)$ or interaction between trial and imidacloprid concentration $\left(F(8.70,313.09)=0.718, p=.687, \eta_{\mathrm{p}}^{2}=\right.$ $.02)$.

\subsection{Behavioural profile}

There was a significant interaction among imidacloprid concentration, behaviour and trial, indicating that bumblebees in the three exposure conditions differed in which behaviours they engaged in across trials $\left(F(34.63,1246.59)=1.879, p=.002, \eta_{\mathrm{p}}{ }^{2}=.05\right)$. Exposed bumblebees were slower across trials to shift from using the pushing strategy to using the inverting to lift strategy, and this occurred in a dose-dependent fashion (Fig. 3.2). A significant interaction between behaviour and trial was also found $(F(17.31,1246.59)=34.884, p<.001$, 
$\eta_{\mathrm{p}}{ }^{2}=.33$ ), indicating that bumblebees behaved differently across trials regardless of imidacloprid exposure. There was a significant main effect of imidacloprid exposure $(F(2,72)=6.016, p=$ $.004, \eta_{\mathrm{p}}{ }^{2}=.14$ ). Post hoc tests revealed that bumblebees exposed at $10 \mathrm{ppb}$ differed behaviourally across trials from unexposed bumblebees $(p=.008)$ and those exposed at $2.6 \mathrm{ppb}$ ( $p=.016$ ), but that unexposed bumblebees and those exposed at $2.6 \mathrm{ppb}$ did not differ ( $p=$ 1.000). There were significant main effects of behaviour $\left(F\left(2.30,82.76=292.169, p<.001, \eta_{\mathrm{p}}{ }^{2}\right.\right.$ $=.80)$ and trial $\left(F(16.38,1179.16)=6.898, p<.001, \eta_{\mathrm{p}}{ }^{2}=.09\right)$, indicating that bumblebees did not engage in behaviours equally, and that behaviour changed across trials. There was no significant interaction between imidacloprid concentration and trial $(F(32.75,1179.16)=1.437$, $\left.p=.053, \eta_{\mathrm{p}}^{2}=.04\right)$ or imidacloprid concentration and behaviour $(F(2.30,82.76)=1.835, p=$ $\left..160, \eta_{\mathrm{p}}^{2}=.05\right)$.

\subsection{Proportion of time inverting to lift the rewarded barrier}

\subsubsection{Trials 1-30}

There was a significant interaction between trial and imidacloprid concentration $\left(F(26.30,946.73)=2.776, p<.001, \eta_{\mathrm{p}}^{2}=.07\right)$. Bumblebees increased the proportion of time inverting to lift the rewarded barrier across trials, but this increase was slower for those exposed to imidacloprid (Fig. 3.3). There was a significant main effect of trial $(F(13.15,946.73)=$ $50.840, p<.001, \eta_{\mathrm{p}}^{2}=.41$ ), indicating that bumblebees increased in proportion of time inverting to lift the rewarded barrier across trials. Post hoc tests revealed that bumblebees spent a lower proportion of time inverting to lift the rewarded barrier on trial 11 than on trial 10 (following overnight retention interval one; $p=.012$ ) and a lower proportion on trial 21 than on trial 20 (following overnight retention interval two; $p<.001$ ). There was no significant main effect of imidacloprid concentration $\left(F(2,72)=1.334, p=.270, \eta_{\mathrm{p}}^{2}=.04\right)$.

\subsubsection{Trials 1-10}

A significant main effect of imidacloprid concentration was found $(F(2,72)=7.275, p=$ $\left..001, \eta_{\mathrm{p}}{ }^{2}=.17\right)$. Post hoc tests revealed that unexposed bumblebees spent a greater proportion of time inverting to lift the rewarded barrier than bumblebees exposed at $10 \mathrm{ppb}(p=.001)$, but that bumblebees exposed at $2.6 \mathrm{ppb}$ did not differ significantly from unexposed bumblebees $(p=$ 
$.417)$ or those exposed at $10 \mathrm{ppb}(p=.075)$. A significant main effect of trial was found ( $F(4.64$, $\left.333.98)=45.798, p<.001, \eta_{\mathrm{p}}{ }^{2}=.39\right)$, indicating that bumblebees increased in proportion of time inverting to lift the rewarded barrier across trials. There was no significant interaction between imidacloprid concentration and trial $\left(F(9.28,333.98)=1.606, p=.110, \eta_{\mathrm{p}}{ }^{2}=.04\right)$.

\subsubsection{Trials 11-20}

A significant main effect of trial was found $\left(F(7.48,538.34)=10.350, p<.001, \eta_{\mathrm{p}}{ }^{2}=\right.$ $.13)$, indicating that bumblebees spent a greater proportion of time inverting to lift the rewarded barrier across trials. There was no significant main effect of imidacloprid concentration $(F(2,72)$ $\left.=1.916, p=.155, \eta_{\mathrm{p}}{ }^{2}=.05\right)$ or interaction between trial and imidacloprid concentration $(F(14.95$, $\left.538.34)=1.466, p=.113, \eta_{\mathrm{p}}^{2}=.04\right)$.

\subsubsection{Trials 21-30}

A significant main effect of trial was found $\left(F(7.42,533.99)=6.620, p<.001, \eta_{\mathrm{p}}{ }^{2}=.08\right)$, indicating that bumblebees spent a greater proportion of time inverting to lift the rewarded barrier across trials. There was no significant main effect of imidacloprid concentration $(F(2,72)$ $\left.=2.042, p=.137, \eta_{\mathrm{p}}^{2}=.05\right)$ or interaction between trial and imidacloprid concentration $(F(14.83$, 533.99) $\left.=0.971, p=.485, \eta_{\mathrm{p}}{ }^{2}=.03\right)$.

\subsection{Proportion of time pushing the rewarded barrier}

\subsubsection{Trials 1-30}

A significant main effect of trial was found $\left(F(12.40,893.12)=19.379, p<.001, \eta_{\mathrm{p}}{ }^{2}=\right.$ $.21)$, indicating that bumblebees differed in the proportion of time they spent pushing the rewarded barrier across trials. Bumblebees spent an increasing proportion of time pushing the rewarded barrier from trial one to trial six, and a generally decreasing proportion of time across remaining trials (Fig. 3.4). There was no significant main effect of imidacloprid concentration $\left(F(2,72)=2.687, p=.075, \eta_{\mathrm{p}}{ }^{2}=.07\right)$ or interaction between trial and imidacloprid concentration $\left(F(24.81,893.12)=1.311, p=.142, \eta_{\mathrm{p}}^{2}=.03\right)$.

\subsubsection{Trials 1-10}


A significant main effect of imidacloprid concentration was found $(F(2,72)=5.041, p=$ $.009, \eta_{\mathrm{p}}^{2}=.12$ ). Post hoc tests revealed that unexposed bumblebees spent a lower proportion of time pushing the rewarded barrier than did bumblebees exposed at $10 \mathrm{ppb}(p=.011)$, however, the difference between bumblebees exposed at 2.6 and $10 \mathrm{ppb}$ fell short of significance $(p=$ $.059)$ and unexposed bumblebees did not differ from those exposed at $2.6 \mathrm{ppb}(p=1.000)$. A significant main effect of trial was found $\left(F(6.38,459.41)=20.955, p<.001, \eta_{\mathrm{p}}{ }^{2}=.22\right)$. Bumblebees increased in proportion of time pushing from trial one to six, but generally decreased across remaining trials. There was no significant interaction between trial and imidacloprid concentration $\left(F(12.76,459.41)=1.137, p=.325, \eta_{\mathrm{p}}^{2}=.03\right)$.

\subsubsection{Trials 11-20}

A significant main effect of trial was found $\left(F(7.09,510.83)=4.410, p<.001, \eta_{\mathrm{p}}^{2}=.06\right)$, indicating that bumblebees spent a lower proportion of time pushing the rewarded barrier across trials. There was no significant main effect of imidacloprid concentration $(F(2,72)=2.241, p=$ $\left..114, \eta_{\mathrm{p}}{ }^{2}=.06\right)$ or interaction between trial and imidacloprid concentration $(F(24.81,893.12)=$ $\left.1.327, p=.185, \eta_{\mathrm{p}}^{2}=.04\right)$.

\subsubsection{Trials 21-30}

A significant main effect of trial was found $\left(F(7.54,543.26)=4.713, p<.001, \eta_{\mathrm{p}}^{2}=.06\right)$. Bumblebees spent a lower proportion of time pushing the rewarded barrier across trials, though bumblebees exposed at $2.6 \mathrm{ppb}$ showed an increase from trial 25 to trial 29 . There was no significant main effect of imidacloprid concentration $\left(F(2,72)=1.035, p=.361, \eta_{\mathrm{p}}^{2}=.03\right)$ or interaction between trial and imidacloprid concentration $\left(F(15.09,543.26)=1.188, p=.276, \eta_{\mathrm{p}}^{2}\right.$ $=.03)$.

\subsection{Proportion of time inverting to lift the non-rewarded barrier}

\subsubsection{Trials 1-30}

A significant main effect of trial was found $\left(F(8.52,613.35)=17.858, p<.001, \eta_{\mathrm{p}}^{2}=\right.$ .20 ), indicating that bumblebees spent a lower proportion of time inverting to lift the nonrewarded barrier across trials (Fig. 3.5). There was no significant main effect of imidacloprid 
concentration $\left(F(2,72)=2.238, p=.114, \eta_{\mathrm{p}}^{2}=.06\right)$ or interaction between trial and imidacloprid concentration $\left(F(17.04,613.35)=1.046, p=.405, \eta_{\mathrm{p}}^{2}=.03\right)$.

\subsubsection{Trials 1-10}

A significant main effect of trial was found $\left(F(4.76,342.43)=18.762, p<.001, \eta_{\mathrm{p}}{ }^{2}=\right.$ .21 ), indicating that bumblebees spent a lower proportion of time inverting to lift the nonrewarded barrier across trials. There was no significant main effect of imidacloprid concentration $\left(F(2,72)=1.080, p=.345, \eta_{\mathrm{p}}^{2}=.03\right)$ or interaction between trial and imidacloprid concentration $\left(F(9.51,342.43)=1.101, p=.361, \eta_{\mathrm{p}}^{2}=.03\right)$.

\subsubsection{Trials 11-20}

There was no significant main effect of trial $\left(F(5.35,385.48)=0.684, p=.646, \eta_{\mathrm{p}}^{2}=.01\right)$ or imidacloprid concentration $\left(F(2,72)=1.864, p=.163, \eta_{\mathrm{p}}{ }^{2}=.05\right)$, and no interaction between trial and imidacloprid concentration $\left(F(10.71,385.48)=0.830, p=.607, \eta_{\mathrm{p}}^{2}=.02\right)$.

\subsubsection{Trials 21-30}

There was no significant main effect of trial $\left(F(2.63,189.73)=1.780, p=.159, \eta_{\mathrm{p}}^{2}=.02\right)$ or imidacloprid concentration $\left(F(2,72)=1.403, p=.252, \eta_{\mathrm{p}}{ }^{2}=.04\right)$, and no interaction between trial and imidacloprid concentration $\left(F(5.27,189.73)=1.139, p=.341, \eta_{\mathrm{p}}{ }^{2}=.03\right)$.

\subsection{Proportion of time pushing the non-rewarded barrier}

\subsubsection{Trials 1-30}

A significant main effect of trial was found $\left(F(11.29,813.02)=35.502, p<.001, \eta_{\mathrm{p}}{ }^{2}=\right.$ .33), indicating that bumblebees spent a lower proportion of time pushing the non-rewarded barrier across trials (Fig. 3.6). There was no significant main effect of imidacloprid concentration $\left(F(2,72)=0.240, p=.787, \eta_{\mathrm{p}}^{2}=.01\right)$ or interaction between trial and imidacloprid concentration $\left(F(22.58,813.02)=1.067, p=.377, \eta_{\mathrm{p}}^{2}=.03\right)$.

\subsubsection{Trials 1-10}

A significant main effect of trial was found $\left(F(5.55,399.64)=60.904, p<.001, \eta_{\mathrm{p}}{ }^{2}=\right.$ 
.46), indicating that bumblebees spent a lower proportion of time pushing the non-rewarded barrier across trials. There was no significant main effect of imidacloprid concentration $(F(2,72)$ $\left.=0.255, p=.775, \eta_{\mathrm{p}}{ }^{2}=.01\right)$ or interaction between trial and imidacloprid concentration $(F(11.10$, $\left.399.64)=1.289, p=.228, \eta_{\mathrm{p}}^{2}=.03\right)$.

\subsubsection{Trials 11-20}

There was no significant main effect of trial $\left(F(5.74,413.41)=2.004, p=.067, \eta_{\mathrm{p}}^{2}=.03\right)$ or imidacloprid concentration $\left(F(2,72)=0.693, p=.503, \eta_{\mathrm{p}}{ }^{2}=.02\right)$, and no interaction between trial and imidacloprid concentration $\left(F(11.48,413.41)=1.330, p=.202, \eta_{\mathrm{p}}^{2}=.04\right)$.

\subsubsection{Trials 21-30}

A significant main effect of trial was found $\left(F(5.98,430.93)=4.530, p<.001, \eta_{\mathrm{p}}{ }^{2}=.06\right)$, indicating that bumblebees spent a lower proportion of time pushing the non-rewarded barrier across trials. There was no significant main effect of imidacloprid concentration $(F(2,72)=$ $\left.0.706, p=.497, \eta_{\mathrm{p}}^{2}=.02\right)$ or interaction between trial and imidacloprid concentration ( $F(11.97$, 430.93) $\left.=0.532, p=.894, \eta_{\mathrm{p}}^{2}=.01\right)$.

\subsection{Overall proportion of time inverting to lift or pushing}

\subsubsection{Trials 1-30}

A significant main effect of imidacloprid concentration was found $(F(2,72)=6.016, p=$ $.004, \eta_{\mathrm{p}}{ }^{2}=.14$; Fig. 3.7). Post hoc tests revealed that bumblebees exposed at $10 \mathrm{ppb}$ spent a greater proportion of time pushing or inverting to lift than unexposed bumblebees $(p=.008)$ and those exposed at $2.6 \mathrm{ppb}(p=.016)$ overall, but that unexposed bumblebees and those exposed at $2.6 \mathrm{ppb}$ did not differ $(p=1.000)$. There was a significant main effect of trial $(F(16.38,1179.16)$ $\left.=6.898, p<.001, \eta_{\mathrm{p}}^{2}=.09\right)$, indicating that bumblebees increased in proportion of time pushing or inverting to lift on day one and declined slightly thereafter, though bumblebees exposed at 10 ppb did not decline. An interaction between imidacloprid concentration and trial fell short of significance $\left(F(32.75,1179.16)=1.437, p=.053, \eta_{\mathrm{p}}^{2}=.04\right)$.

\subsubsection{Trials 1-10}


A significant main effect of trial was found $\left(F(6.49,467.15)=15.436, p<.001, \eta_{\mathrm{p}}{ }^{2}=\right.$ $.18)$, indicating that bumblebees spent a greater proportion of time pushing or inverting to lift across trials. There was no significant main effect of imidacloprid concentration $(F(2,72)=$ $\left.0.431, p=.652, \eta_{\mathrm{p}}{ }^{2}=.01\right)$ or interaction between trial and imidacloprid concentration $(F(12.98$, $\left.467.15)=1.223, p=.259, \eta_{\mathrm{p}}^{2}=.03\right)$.

\subsubsection{Trials 11-20}

A significant main effect of imidacloprid concentration was found $(F(2,72)=5.657, p=$ $\left..005, \eta_{\mathrm{p}}{ }^{2}=.14\right)$. Post hoc tests revealed that bumblebees exposed at $10 \mathrm{ppb}$ spent a greater proportion of time pushing or inverting to lift than unexposed bumblebees $(p=.009)$ and those exposed at $2.6 \mathrm{ppb}(p=.024)$ overall, but that unexposed bumblebees and those exposed at 2.6 ppb did not differ $(p=1.000)$. There was no significant main effect of trial $(F(7.15,514.96)=$ $\left.0.852, p=.547, \eta_{\mathrm{p}}^{2}=.01\right)$ or interaction between trial and imidacloprid concentration $(F(14.30$, 514.96) $\left.=1.269, p=.221, \eta_{\mathrm{p}}^{2}=.03\right)$.

\subsubsection{Trials 21-30}

A significant main effect of imidacloprid concentration was found $(F(2,72)=9.017, p<$ $\left..001, \eta_{\mathrm{p}}^{2}=.20\right)$. Post hoc tests revealed that bumblebees exposed at $10 \mathrm{ppb}$ spent a greater proportion of time pushing or inverting to lift than unexposed bumblebees $(p<.001)$ and those exposed at $2.6 \mathrm{ppb}(p=.012)$ overall, but that unexposed bumblebees and those exposed at 2.6 ppb did not differ $(p=.790)$. There was no significant main effect of trial $(F(7.43,535.04)=$ $\left.1.062, p=.387, \eta_{\mathrm{p}}^{2}=.01\right)$ or interaction between trial and imidacloprid concentration $(F(14.86$, $\left.535.04)=0.570, p=.897, \eta_{\mathrm{p}}^{2}=.02\right)$.

\subsection{Behaviour switching}

\subsubsection{Trials 1-30}

A significant main effect of imidacloprid concentration was found $(F(2,72)=6.859, p=$ $.002, \eta_{\mathrm{p}}^{2}=.16$; Fig. 3.8). Post hoc tests revealed that unexposed bumblebees switched between behaviours at a higher rate than bumblebees exposed at $2.6(p=.006)$ and $10 \mathrm{ppb}(p=.006)$, but that bumblebees exposed at 2.6 and $10 \mathrm{ppb}$ did not differ $(p=1.000)$. There was a significant 
main effect of trial $\left(F(17.91,1289.90)=2.334, p=.001, \eta_{\mathrm{p}}{ }^{2}=.03\right)$. Bumblebees showed a high rate of switching on trial one which generally decreased until it rose again following trial seven. There was no significant interaction between trial and imidacloprid concentration $(F(35.83$, $\left.1289.90)=1.231, p=.166, \eta_{\mathrm{p}}^{2}=.03\right)$.

\subsubsection{Trials 1-10}

A significant main effect of imidacloprid concentration was found $(F(2,72)=10.783, p<$ $\left..001, \eta_{\mathrm{p}}{ }^{2}=.23\right)$. Post hoc tests revealed that unexposed bumblebees switched between behaviours at a higher rate than bumblebees exposed at $2.6(p=.005)$ and $10 \mathrm{ppb}(p<.001)$, but that bumblebees exposed at 2.6 and $10 \mathrm{ppb}$ did not differ $(p=.719)$. There was a significant main effect of trial $\left(F(17.16,515.40)=6.663, p<.001, \eta_{\mathrm{p}}^{2}=.08\right)$. Bumblebees showed a high rate of switching on trial one which generally decreased across trials on day one but rose following trial seven. There was no significant interaction between trial and imidacloprid concentration $\left(F(14.32,515.40)=0.968, p=.486, \eta_{\mathrm{p}}^{2}=.03\right)$.

\subsubsection{Trials 11-20}

There was no significant main effect of trial $\left(F(7.84,564.79)=0.253, p=.979, \eta_{\mathrm{p}}{ }^{2}=.01\right)$ or imidacloprid concentration $\left(F(2,72)=1.864, p=.162, \eta_{\mathrm{p}}{ }^{2}=.05\right)$, and no interaction between trial and imidacloprid concentration $\left(F(15.69,564.79)=1.479, p=.103, \eta_{\mathrm{p}}{ }^{2}=.04\right)$.

\subsubsection{Trials 21-30}

A significant main effect of imidacloprid concentration was found $(F(2,72)=3.705, p=$ $\left..029, \eta_{\mathrm{p}}{ }^{2}=.09\right)$. Post hoc tests revealed that unexposed bumblebees switched between behaviours at a higher rate than bumblebees exposed at $2.6(p=.028)$, but that those exposed at $10 \mathrm{ppb}$ did not differ from unexposed bumblebees $(p=.237)$ or those exposed at $2.6 \mathrm{ppb}(p=1.000)$. There was no significant main effect of trial $\left(F(7.38,531.56)=1.085, p=.372, \eta_{\mathrm{p}}{ }^{2}=.01\right)$ or interaction between trial and imidacloprid concentration $\left(F(14.76,531.56)=0.977, p=.478, \eta_{\mathrm{p}}{ }^{2}=.03\right)$.

\subsection{Inter-trial interval}

\subsubsection{Intervals 1-27}


There was a significant interaction between trial and imidacloprid concentration $\left(F(19.79,712.35)=1.686, p=.031, \eta_{\mathrm{p}}^{2}=.04\right)$. Inter-trial interval was generally longer for bumblebees exposed at $10 \mathrm{ppb}$ across the first 10 trials, but similar for bumblebees in all conditions thereafter (Fig. 3.9). A significant main effect of trial was found $(F(9.89,712.35)=$ $\left.4.619, p<.001, \eta_{\mathrm{p}}{ }^{2}=.06\right)$, indicating inter-trial interval decreased across trials. There was no significant main effect of imidacloprid concentration $\left(F(2,72)=1.010, p=.369, \eta_{\mathrm{p}}{ }^{2}=.03\right)$.

\subsubsection{Intervals 1-9}

A significant main effect of imidacloprid concentration was found $(F(2,72)=9.312, p<$ $\left..001, \eta_{\mathrm{p}}{ }^{2}=.20\right)$. Post hoc tests revealed that inter-trial interval was longer for bumblebees exposed at $10 \mathrm{ppb}$ relative to unexposed bumblebees $(p=.001)$ and those exposed at $2.6 \mathrm{ppb}(p$ $=.001)$, but similar between unexposed bumblebees and those exposed at $2.6(p=1.000)$. There was a significant main effect of trial $\left(F(3.03,218.00)=8.653, p<.001, \eta_{\mathrm{p}}^{2}=.11\right)$, indicating inter-trial interval decreased across trials. There was no significant interaction between trial and imidacloprid concentration $\left(F(6.06,218.00)=1.279, p=.268, \eta_{\mathrm{p}}^{2}=.03\right)$.

\subsubsection{Intervals 10-18}

There was no significant main effect of trial $\left(F(4.06,292.40)=1.913, p=.107, \eta_{\mathrm{p}}{ }^{2}=.03\right)$ or imidacloprid concentration $\left(F(2,72)=0.193, p=.825, \eta_{\mathrm{p}}^{2}<.01\right)$, and no interaction between trial and imidacloprid concentration $\left(F(8.12,292.40)=1.072, p=.383, \eta_{\mathrm{p}}^{2}=.03\right)$.

\subsubsection{Intervals 19-27}

There was no significant main effect of trial $\left(F(4.72,340.13)=0.423, p=.823, \eta_{\mathrm{p}}^{2}=.01\right)$ or imidacloprid concentration $\left(F(2,72)=1.273, p=.286, \eta_{\mathrm{p}}{ }^{2}=.03\right)$, and no interaction between trial and imidacloprid concentration $\left(F(9.45,340.13)=1.414, p=.177, \eta_{\mathrm{p}}^{2}=.04\right)$.

\subsubsection{Inter-trial interval and latency to remove the rewarded barrier}

There was a positive correlation between inter-trial interval and latency to remove the rewarded barrier $(\mathrm{r}=.44, p<.001)$, indicating that bumblebees with shorter inter-trial intervals were faster to remove the rewarded barrier overall. The relationship was close to significance for unexposed bumblebees $(\mathrm{r}=.39, p=.054)$, significant for those exposed at $2.6 \mathrm{ppb}(\mathrm{r}=.56, p=$ 
$.004)$ and non-significant for those exposed at $10 \mathrm{ppb}(\mathrm{r}=.28, p=.173$; Fig. 3.10)

\subsection{Body size}

Bumblebees did not differ in thorax width by condition $\left(F(2,59)=2.004, p=.144, \eta_{\mathrm{p}}{ }^{2}=\right.$ .07). Thorax width and latency to remove the rewarded barrier were not related in unexposed bumblebees $(\mathrm{r}=-.31, p=.200)$, those exposed at $2.6 \mathrm{ppb}(\mathrm{r}=-.26, p=.247)$, those exposed at 10 ppb $(\mathrm{r}=.05, p=.834)$ or overall $(\mathrm{r}=-.05, p=.681$; Fig. 3.11).

\subsection{Colony exposure duration prior to testing}

Colony exposure duration prior to testing for individual bumblebees did not differ by condition $\left(F(2,72)=2.859, p=.064, \eta_{\mathrm{p}}^{2}=.07\right)$. Exposure duration prior to testing and latency to remove the rewarded barrier were not related in unexposed bumblebees $(\mathrm{r}=-.15, p=.467)$, those exposed at $2.6 \mathrm{ppb}(\mathrm{r}=-.09, p=.669)$, those exposed at $10 \mathrm{ppb}(\mathrm{r}=-.04, p=.847)$ or overall $(\mathrm{r}=$ $-.09, p=.436$; Fig. 3.12).

\subsection{Colony differences in latency to remove the rewarded barrier}

\subsubsection{Colonies exposed at 0 ppb}

There was a significant main effect of trial $\left(F(7.45,164.00)=20.176, p<.001, \eta_{\mathrm{p}}{ }^{2}=\right.$ .48), indicating that bumblebees became faster to remove the rewarded barrier across trials overall. There was no significant main effect of colony $\left(F(2,22)=0.741, p=.488, \eta_{\mathrm{p}}^{2}=.06\right)$ or interaction between trial and colony $\left(F(14.91,164.00)=0.849, p=.621, \eta_{\mathrm{p}}^{2}=.07\right)$, however, indicating that colonies exposed at 0 ppb performed similarly (Fig 3.13a).

\subsubsection{Colonies exposed at 2.6 ppb}

There was a significant main effect of trial $\left(F(7.05,155.13)=11.064, p<.001, \eta_{\mathrm{p}}^{2}=\right.$ $.33)$, indicating that bumblebees became faster to remove the rewarded barrier across trials overall. There was also a significant main effect of colony $\left(F(2,22)=8.278, p=.002, \eta_{\mathrm{p}}^{2}=.43\right)$, indicating colonies exposed at 2.6 performed differently (Fig. 3.13b). Post hoc tests revealed bumblebees from colony one and three performed similarly ( $p=1.000)$, but that bumblebees from colony two were slower to remove the rewarded barrier than those from colony one ( $p=$ 
$.006)$ and three $(p=.007)$. There was no significant interaction between trial and colony $\left(F(14.10,155.13)=0.982, p=.475, \eta_{\mathrm{p}}^{2}=.08\right)$.

\subsubsection{Colonies exposed at $10 \mathrm{ppb}$}

There was a significant main effect of trial $\left(F(7.17,157.73)=28.180, p<.001, \eta_{\mathrm{p}}^{2}=\right.$ .56), indicating that bumblebees became faster to remove the rewarded barrier across trials overall. There was no significant main effect of colony $\left(F(2,22)=0.813, p=.457, \eta_{\mathrm{p}}{ }^{2}=.07\right)$ or interaction between trial and colony $\left(F(14.40,157.73)=1.108, p=.354, \eta_{\mathrm{p}}^{2}=.07\right)$, however, indicating that colonies exposed at $10 \mathrm{ppb}$ performed similarly (Fig. 3.13c). 


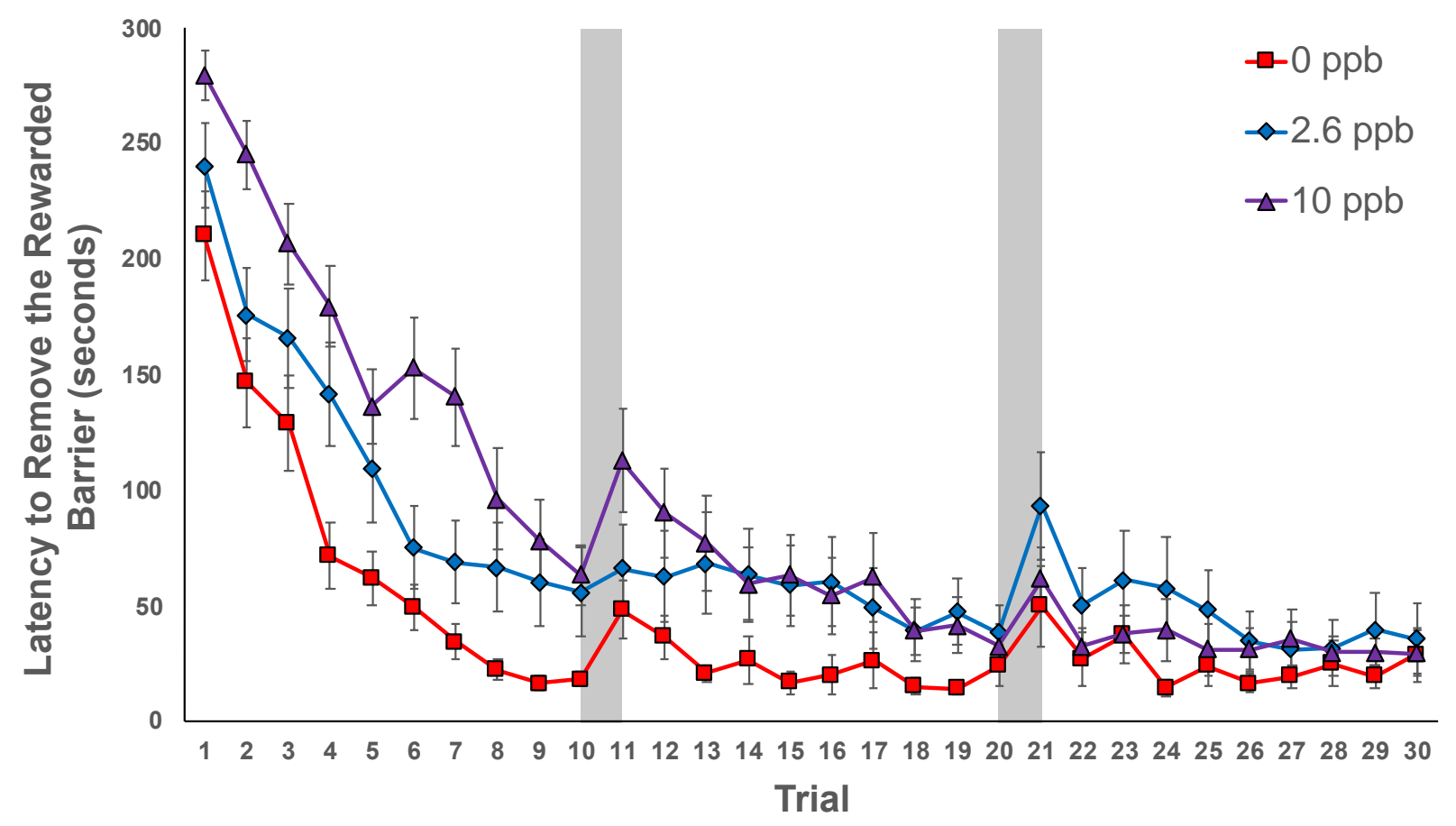

Figure 3.1. Latency to remove the rewarded barrier. Imidacloprid-exposed bumblebees showed a dose-dependent increase in latency to remove the rewarded barrier, but all bees performed similarly by trial 30 . Vertical bars represent overnight retention intervals between days one and two and between days two and three. Bumblebees were slower to remove the rewarded barrier following the second overnight retention interval, but not the first. Error bars equal \pm 1 standard error of the mean. 

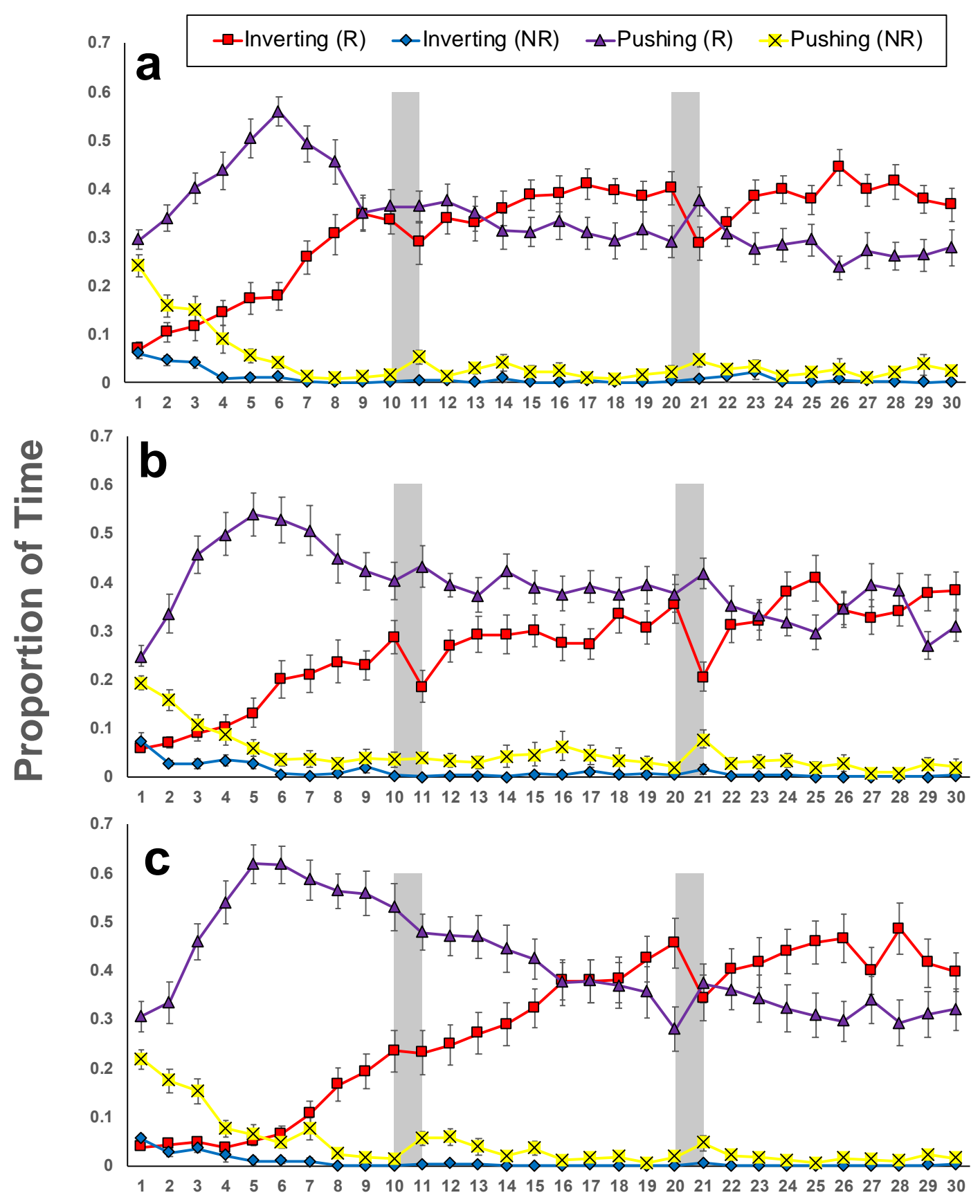

Trial

Figure 3.2. Proportion of time engaging in four behaviours: inverting to lift the rewarded and non-rewarded barriers and pushing the rewarded and non-rewarded barriers. Unexposed bumblebees (a) and bumblebees exposed at $2.6 \mathrm{ppb}$ (b) behaved similarly, but those exposed at $10 \mathrm{ppb}$ (c) took longer to shift to the strategy of inverting to lift the plastic barrier. Bumblebees in all conditions rapidly abandoned the non-rewarded barrier. Error bars equal \pm 1 standard error of the mean. 


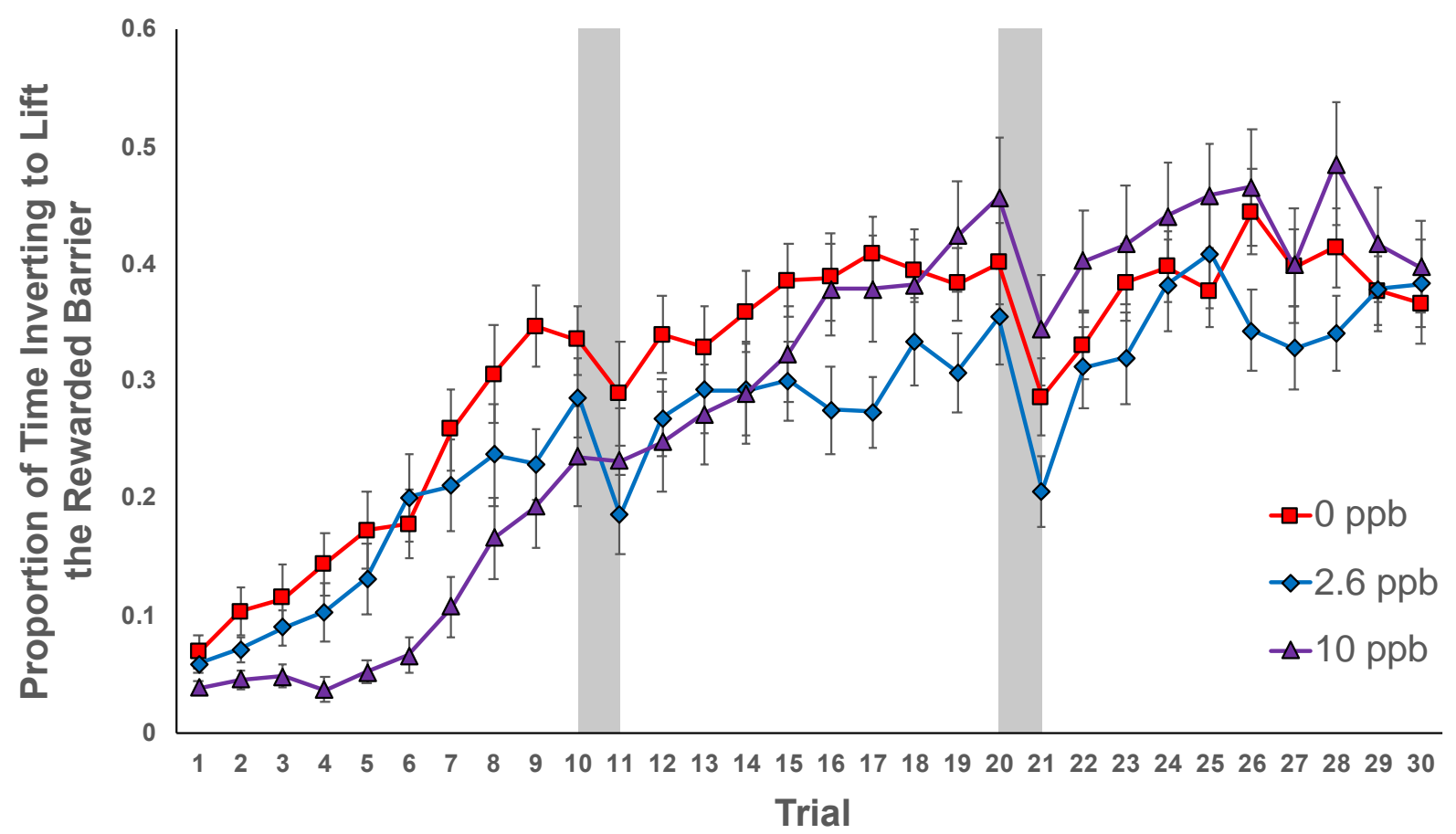

Figure 3.3. Proportion of time inverting to lift the rewarded barrier. Bumblebees in all conditions spent a greater proportion of time inverting to lift the rewarded barrier across trials but this increase was slowest for bumblebees exposed at $10 \mathrm{ppb}$. Bumblebees showed reductions in inverting to lift the rewarded barrier after both overnight retention intervals. Error bars equal \pm 1 standard error of the mean. 


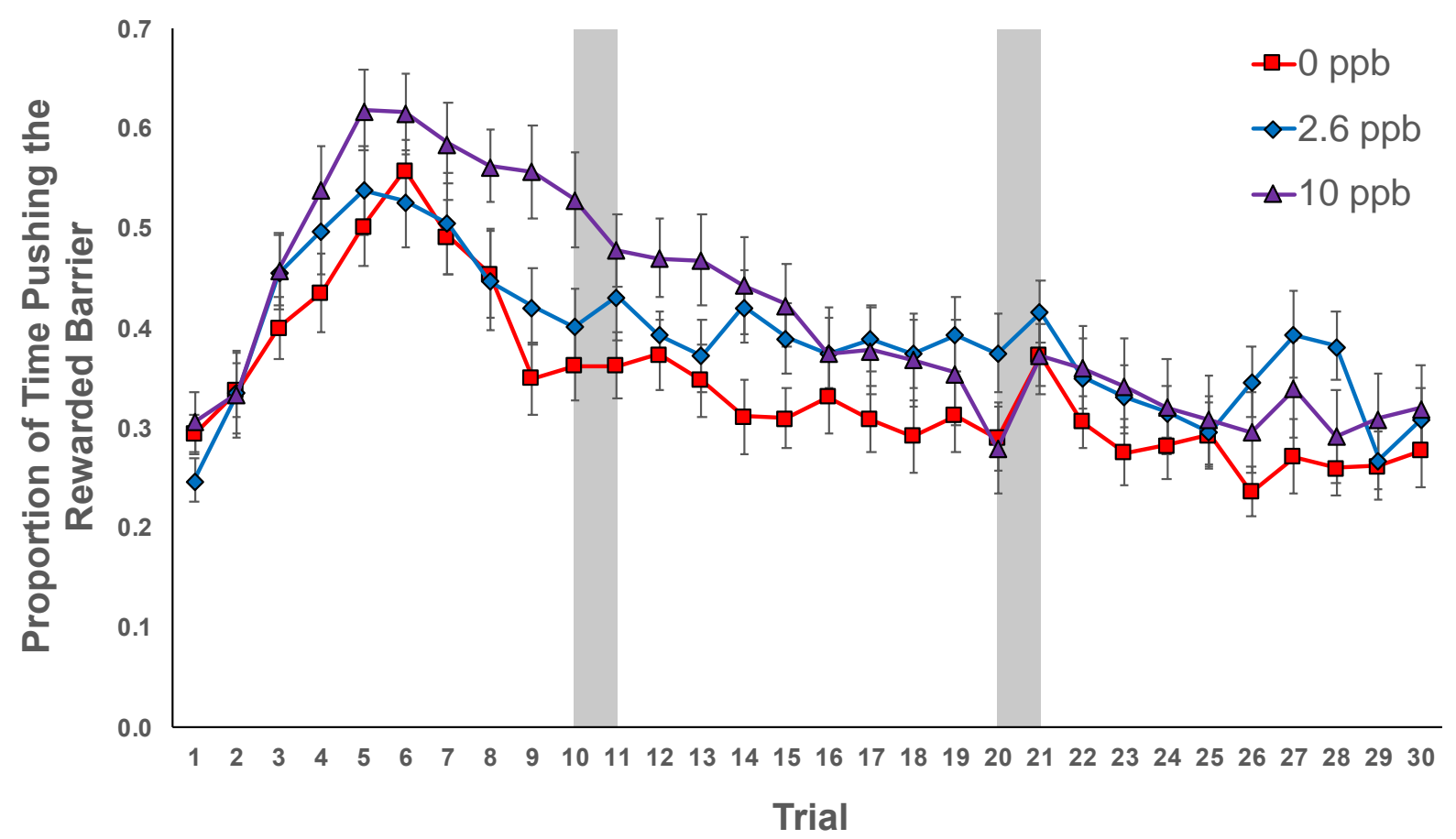

Figure 3.4. Proportion of time pushing the rewarded barrier. Bumblebees increased in proportion of time pushing the rewarded barrier to trial six and decreased thereafter. Bumblebees exposed at $10 \mathrm{ppb}$ experienced the greatest increase up to trial six and decreased at the slowest rate. Error bars equal \pm 1 standard error of the mean. 


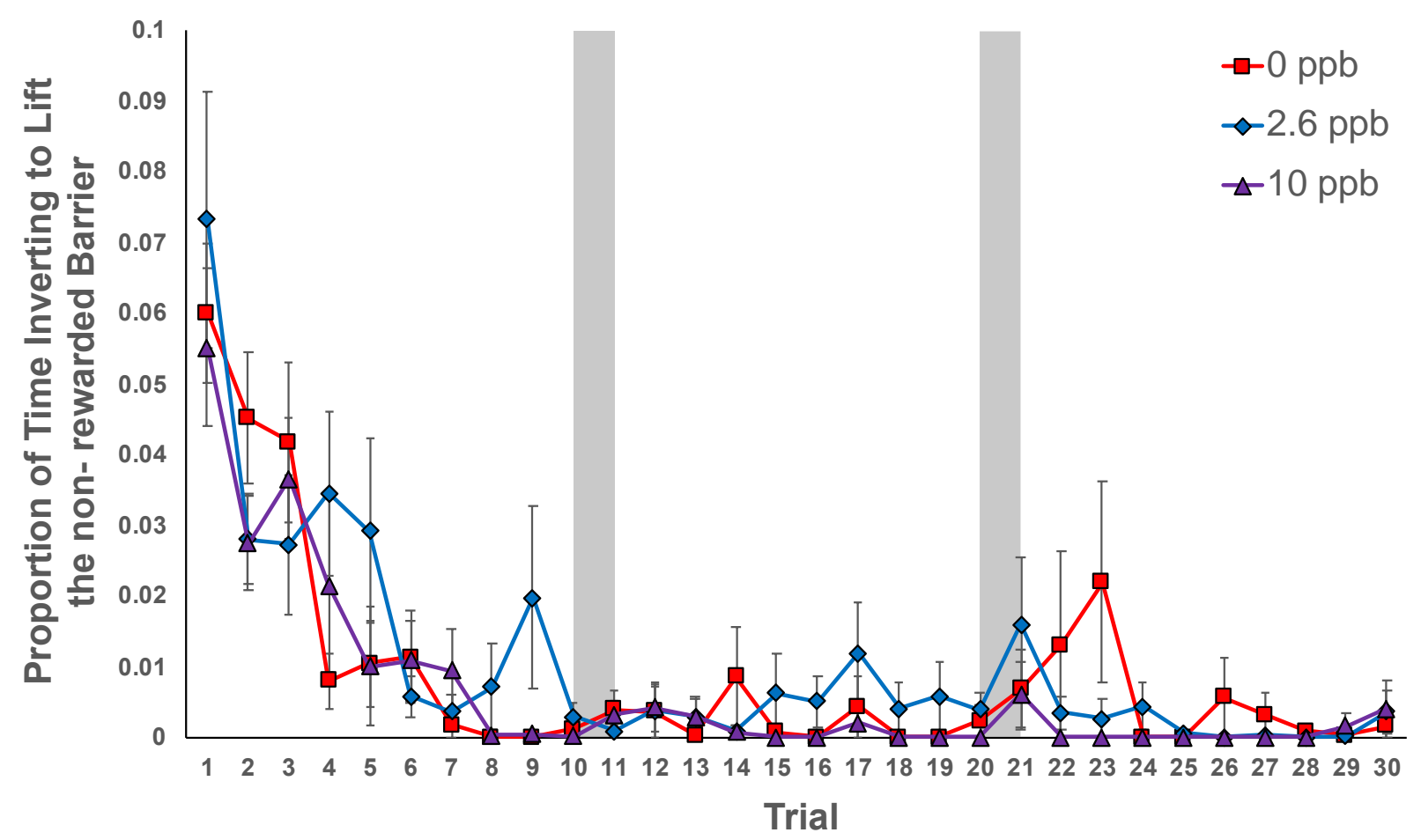

Figure 3.5. Proportion of time inverting to lift the non-rewarded barrier. Bumblebees in all conditions decreased in proportion of time inverting to lift the non-rewarded barrier on day one and rarely inverted to lift it thereafter. Errors bars equal \pm 1 standard error of the mean. 


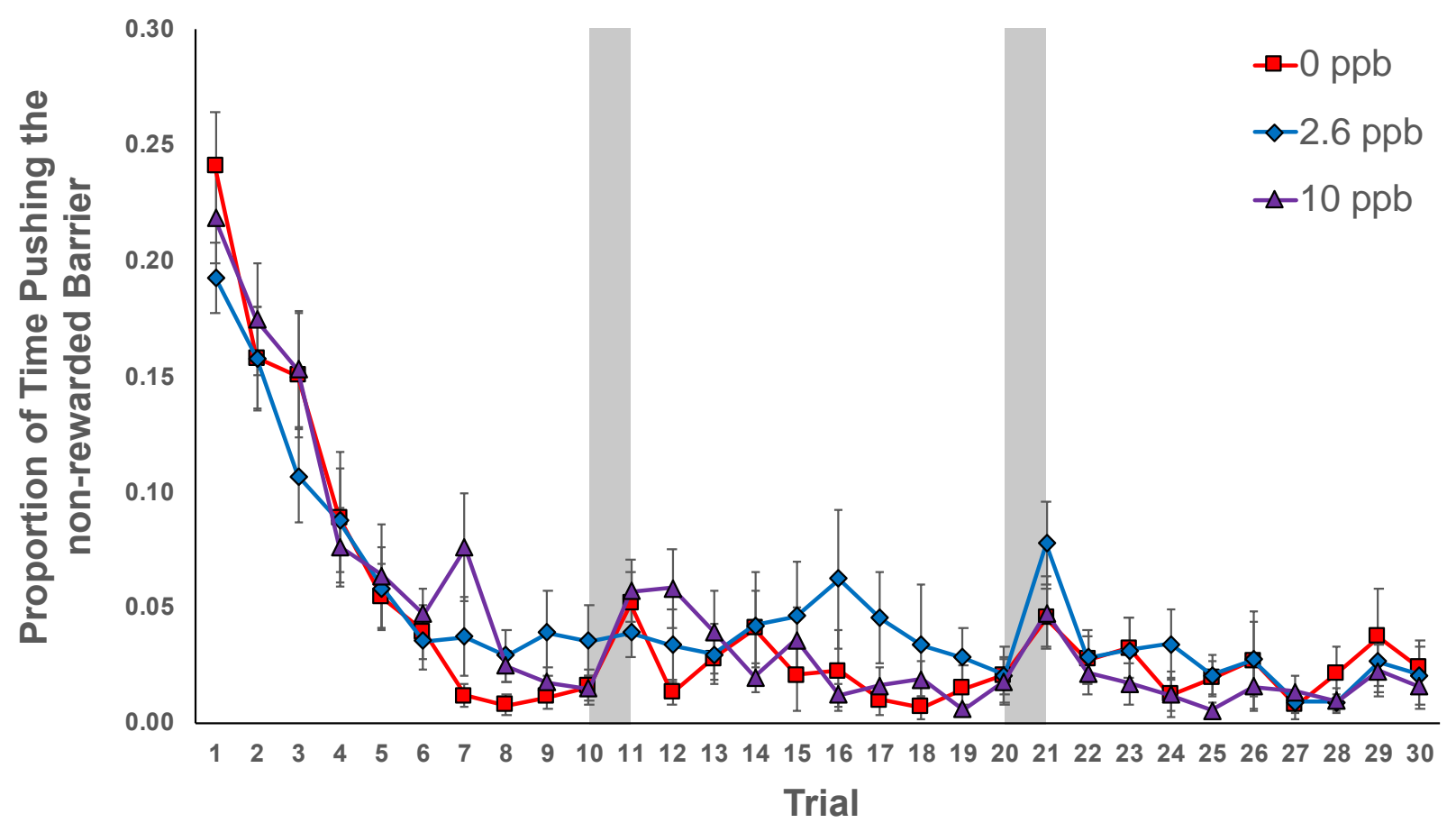

Figure 3.6. Proportion of time pushing the non-rewarded barrier. Bumblebees in all conditions decreased in proportion of time pushing the non-rewarded barrier on day one and rarely pushed it thereafter. Errors bars equal \pm 1 standard error of the mean. 


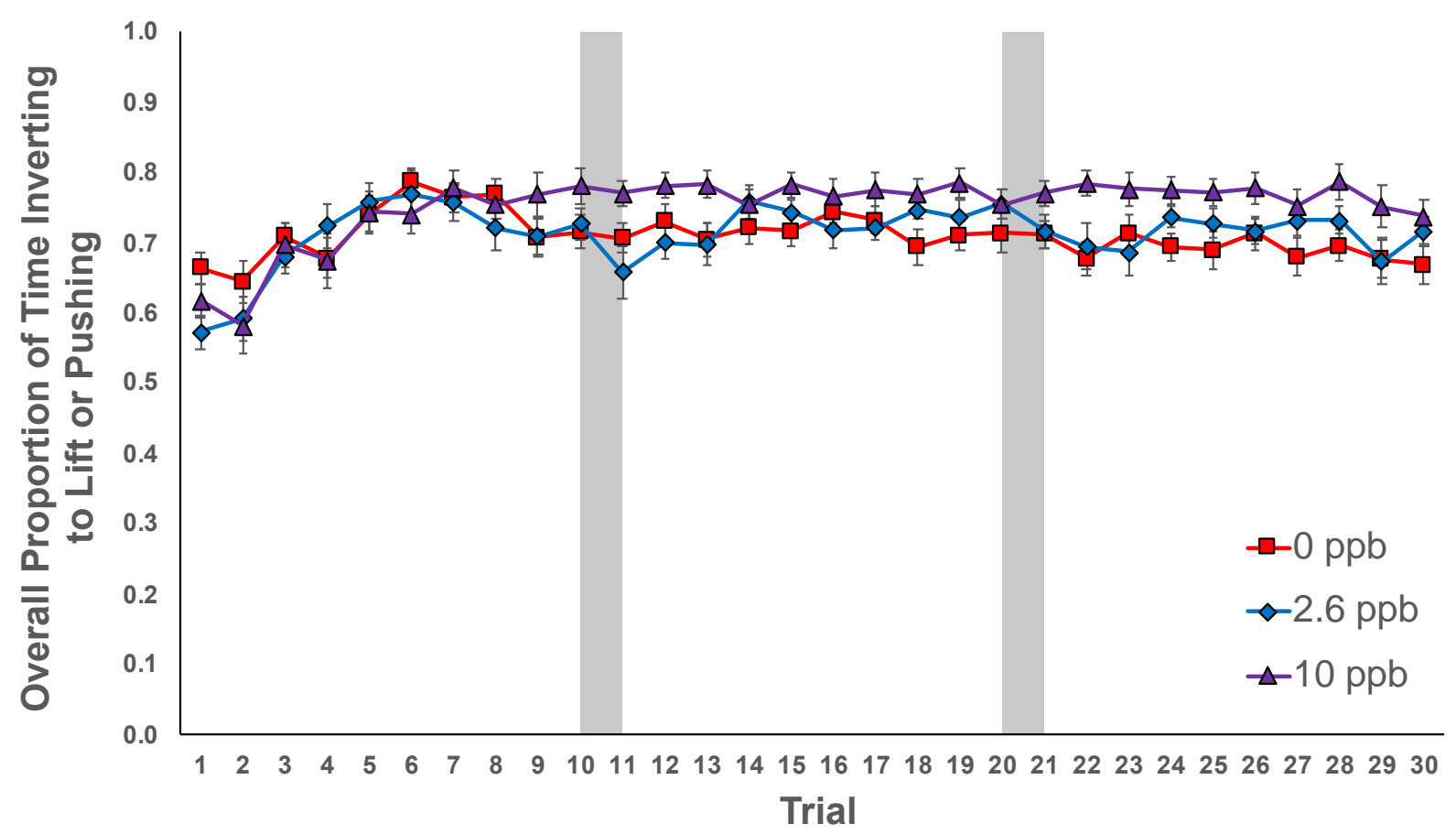

Figure 3.7. Overall proportion of time inverting to lift or pushing either barrier. Bumblebees increased overall in proportion of time inverting to lift or pushing on day one and remained stable thereafter, with bumblebees exposed at $10 \mathrm{ppb}$ spending a slightly greater proportion of time inverting to lift of pushing. Error bars equal \pm 1 standard error of the mean. 


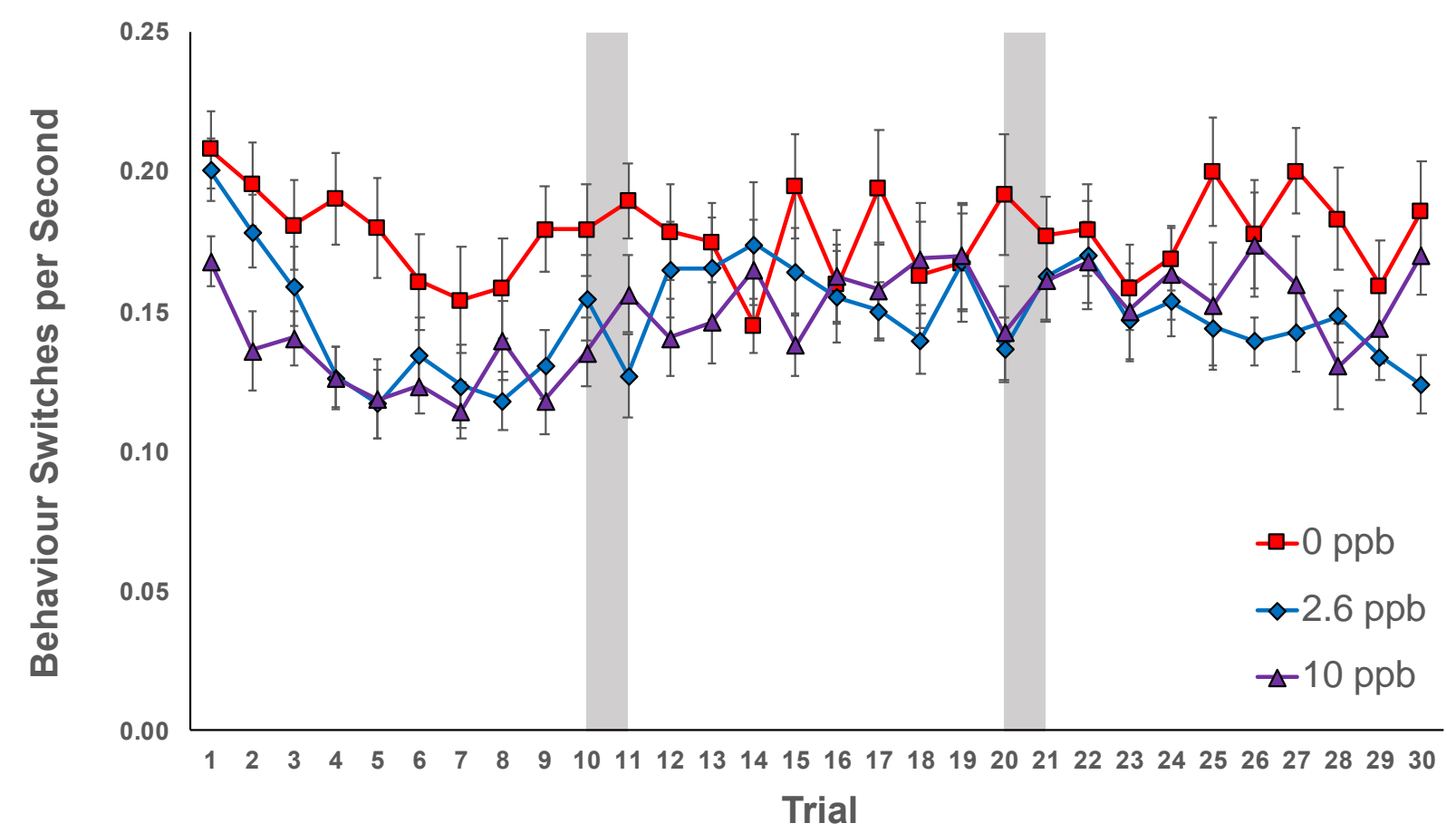

Figure 3.8. Number of behaviour switches per second. Unexposed bumblebees switched between behaviours at a higher rate than did bumblebees exposed at 2.6 or 10 ppb during early trials. Errors bars equal \pm 1 standard error of the mean. 


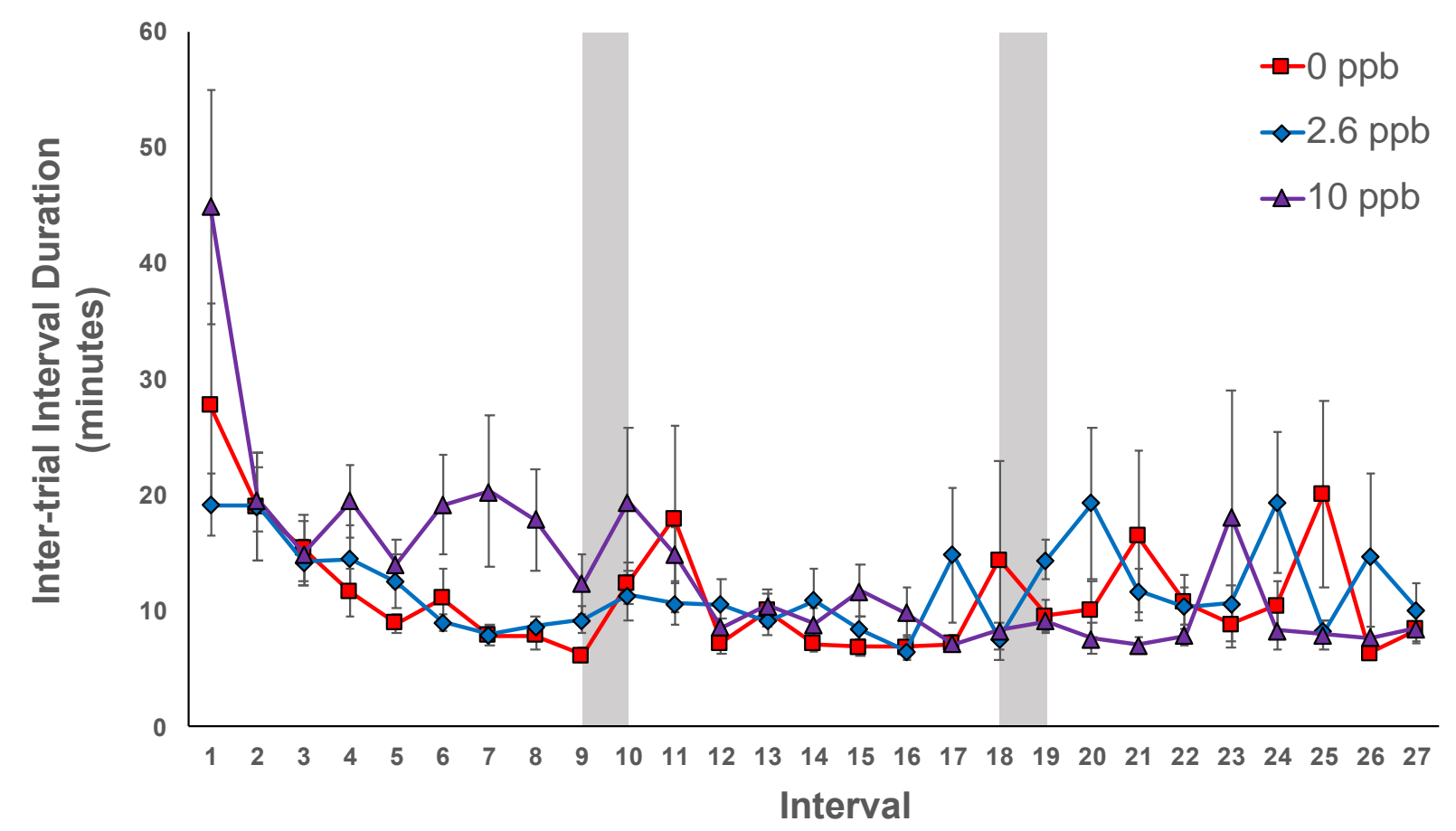

Figure 3.9. Inter-trial interval in minutes. Bumblebees exposed at $10 \mathrm{ppb}$ took longer between trials during day one than did unexposed bumblebees and those exposed at $2.6 \mathrm{ppb}$. Error bars equal \pm 1 standard error of the mean. 


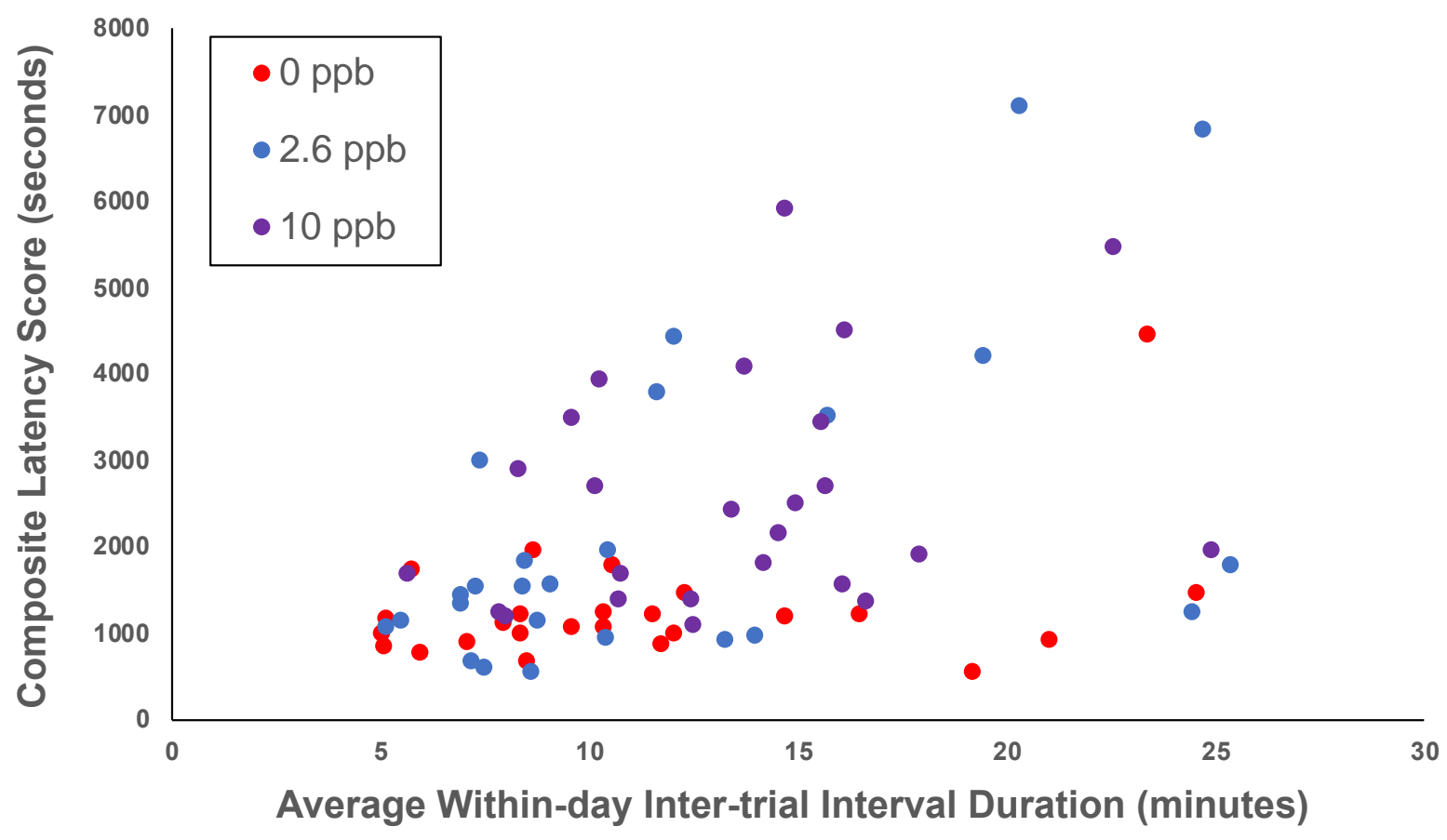

Figure 3.10. Composite latency as a function of average within-day inter-trial interval duration. Bumblebees with longer within-day inter-trial intervals were slower to remove the rewarded barrier overall $(\mathrm{r}=.44)$. This relationship was significant for bumblebees exposed at $2.6 \mathrm{ppb}(\mathrm{r}=$ $.56)$, close to significant for unexposed bumblebees $(r=.39)$ and non-significant for those exposed at $10 \mathrm{ppb}(\mathrm{r}=.28)$. 


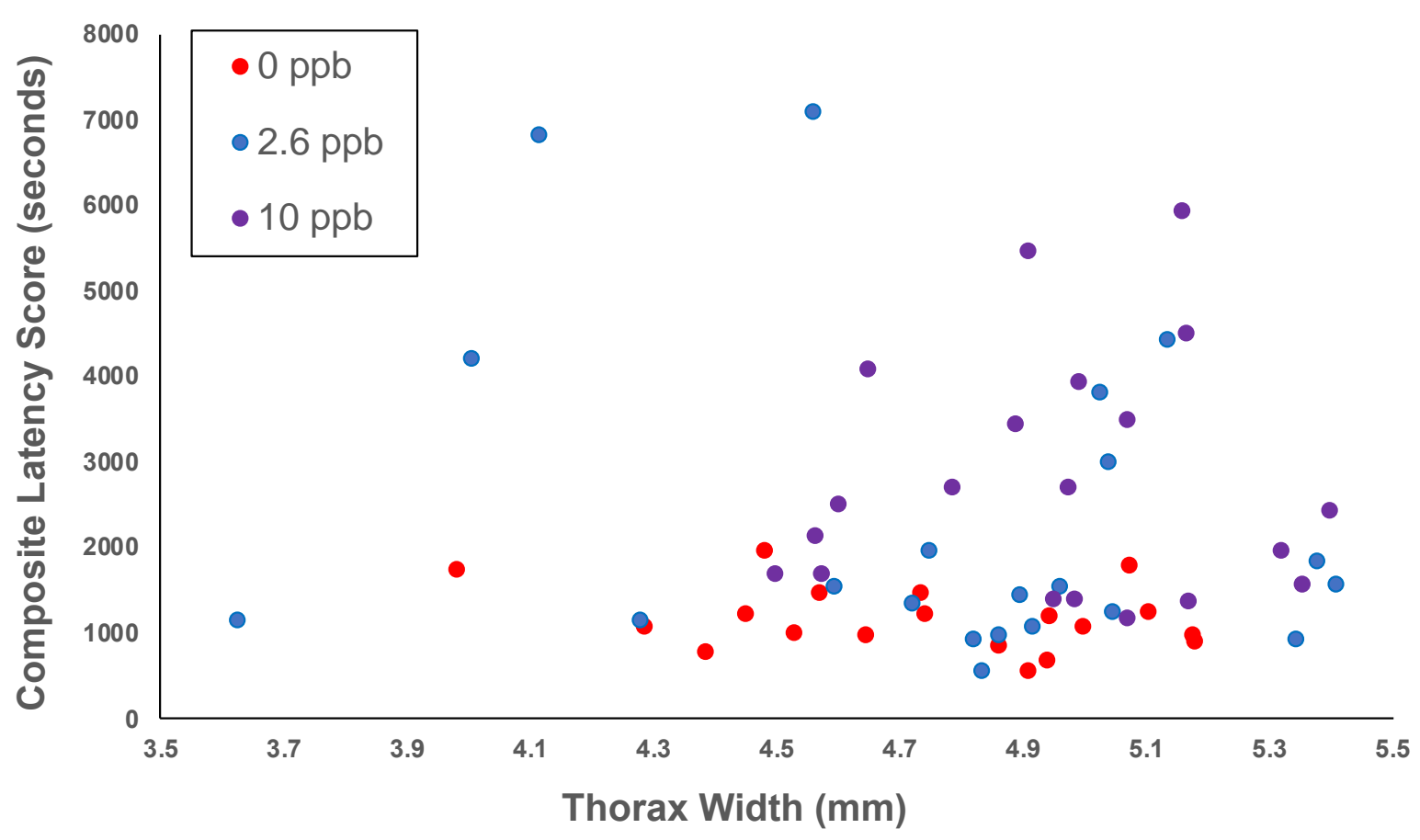

Figure 3.11. Composite latency as a function of thorax width. There was no relationship between thorax width and composite latency $(r=-.05)$. Bumblebee thorax width did not vary by condition. 


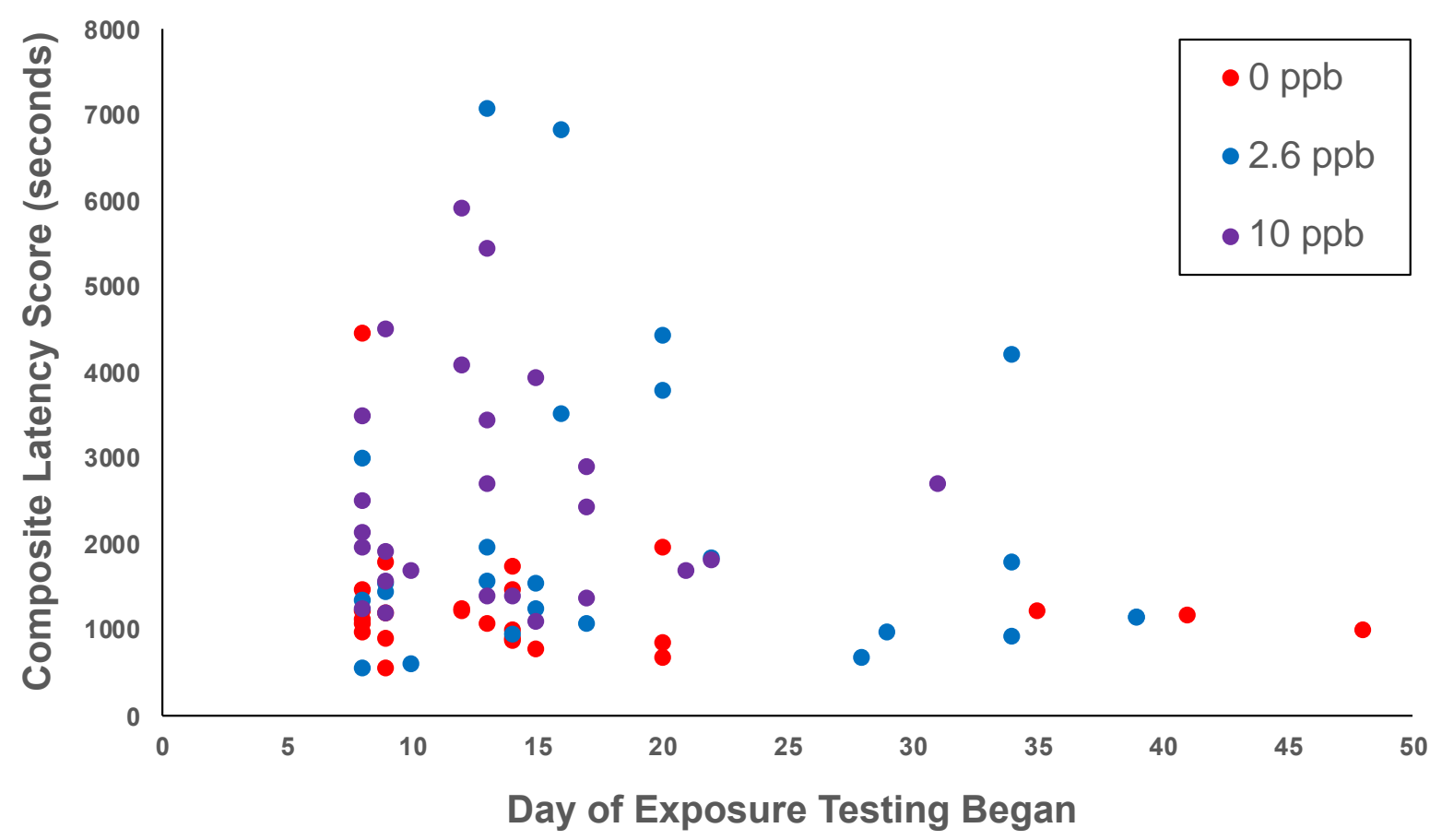

Figure 3.12. Composite latency as a function of the day of colony exposure on which individual bumblebees began testing. There was no relationship between composite latency and colony exposure duration prior to testing $(r=-.09)$. Colony exposure duration prior to testing did not vary by condition. 


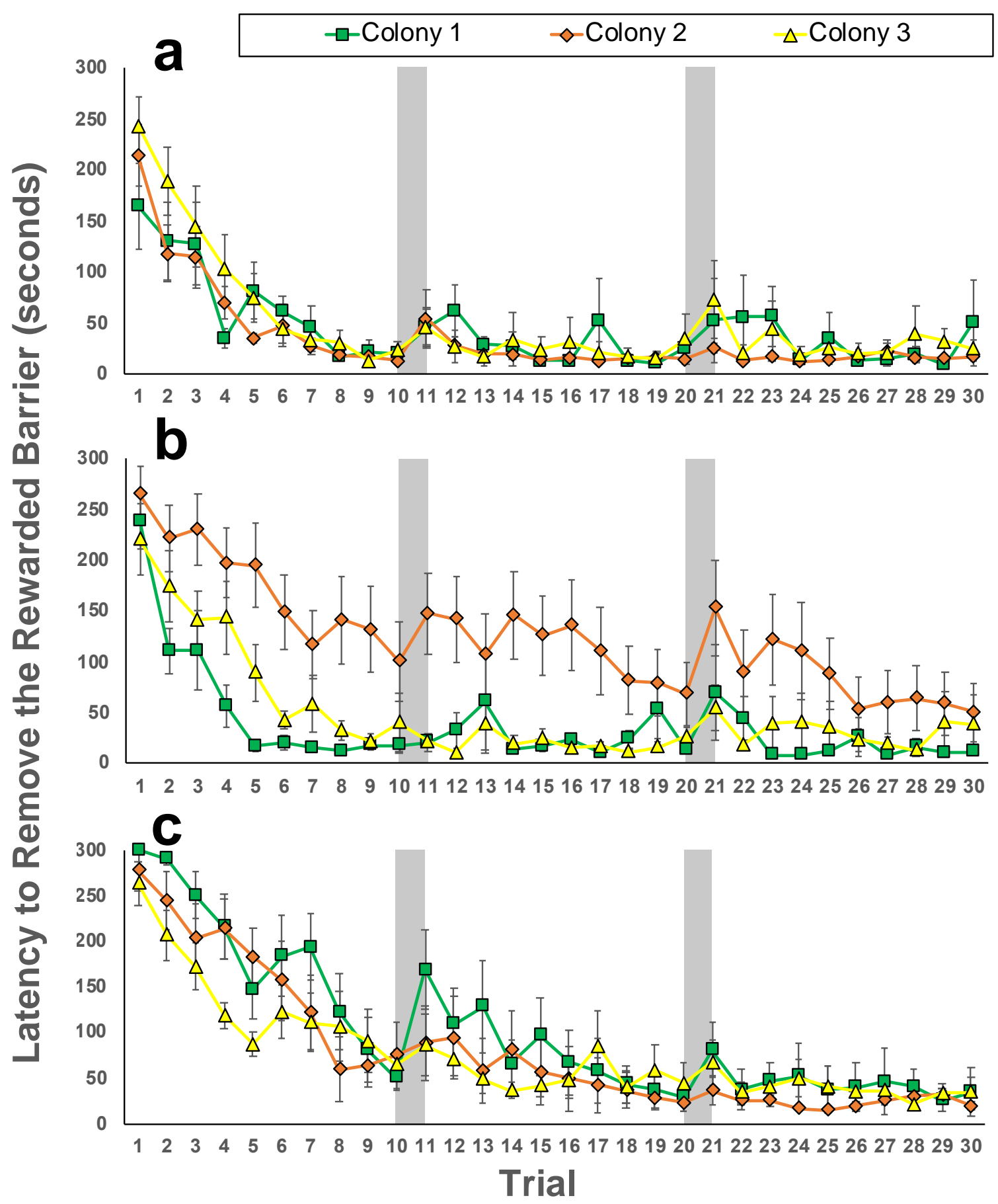

Figure 3.13. Latency to remove the rewarded barrier. Bumblebees from (a) unexposed colonies one $(n=7)$, two $(n=9)$ and three $(n=9)$ performed similarly. Bumblebees from (b) $2.6 \mathrm{ppb}$ imidacloprid-exposed colony two $(n=9)$ were slower to remove the rewarded barrier than those from colony one $(n=6)$ and three $(n=10)$. Bumblebees from (c) $10 \mathrm{ppb}$ imidacloprid-exposed colonies one $(\mathrm{n}=8)$, two $(\mathrm{n}=8)$ and three $(\mathrm{n}=9)$ performed similarly. Error bars equal \pm 1 standard error of the mean. 


\section{Chapter 4}

\section{Discussion}

A model of flower handling was used to assess the effects of imidacloprid, a common neonicotinoid pesticide, on motor learning in bumblebees. As predicted, imidacloprid-exposed bumblebees showed a delay in learning to solve the motor task. Exposed bumblebees showed a strong dose-dependent delay to solve the task during the first day of testing. However, this dosedependent effect diminished over time. The effect was much less pronounced on day two and bumblebees performed similarly regardless of exposure by the end of testing on day three. These results are consistent with those of Stanley \& Raine (2016), which showed that bumblebees chronically exposed to the neonicotinoid thiamethoxam at $10 \mathrm{ppb}$ took more trials to learn to handle morphologically complex flowers. I also found some evidence for overnight forgetting on the task, though not as a function of imidacloprid exposure. Bumblebees were slower to solve the task following the second overnight retention interval but not the first. Chittka (1998) found no evidence for overnight forgetting in bumblebees on a motor learning task, but bumblebees in the present study were given fewer learning trials which may explain the discrepancy. Interestingly, bumblebees showed overnight forgetting following 277-354 flower visits on day one in a study by Raine and Chittka (2007). Consistent with Strang (2018), bumblebees improved significantly across trials. Increased efficiency of bumblebees on the task following experience parallels observations of bumblebees learning to forage on real flowers (Heinrich, 1979; Laverty, 1980; Peat \& Goulson, 2005; Raine \& Chittka, 2007).

A novel contribution of the present study was detailed analysis of the effect of imidacloprid on the behaviour of bumblebees engaged in motor learning. Bumblebees used two dominant behavioural strategies to solve the task: inverting in the tube to lift the rewarded barrier and pushing the rewarded barrier. Only inverting, however, was successful, which is consistent with Strang (2018). Bumblebees favoured the pushing strategy during early trials, likely because of its relative simplicity, but shifted to using the inverting to lift strategy after learning it was the most effective. As predicted, bumblebees exposed to imidacloprid at $10 \mathrm{ppb}$ were much slower to shift from pushing to inverting to lift; they showed the strongest preference for pushing during early trials and spent much less time inverting to lift on day one than did bumblebees exposed at 0 or $2.6 \mathrm{ppb}$. While unexposed bumblebees and those exposed at $2.6 \mathrm{ppb}$ split time about evenly 
between pushing and inverting to lift by the end of day one, bumblebees exposed at $10 \mathrm{ppb}$ did not until midway through day two. Unexposed bumblebees showed a slightly stronger preference for inverting to lift than those exposed at $2.6 \mathrm{ppb}$ across early trials, however, this difference was not statistically significant. The delay in exposed bumblebees to use the successful strategy is consistent with the delay in solving the task, indicating that exposed bumblebees were slower to solve the task as a direct result of delayed use of the successful strategy. Bumblebees spent a lower proportion of time inverting to lift following overnight retention intervals, which may explain why they were slower to solve the task following the second overnight retention interval.

Why were exposed bumblebees slower to use the successful behavioural strategy? The reason is not that exposed bumblebees were less active. Indeed, bumblebees in all conditions spent a similar amount of time interacting with the two barriers. Further, it is not the case that exposed bumblebees spent more time interacting with the unrewarded metal barrier. Bumblebees in all conditions decreased equally in proportion of time interacting with the unrewarded barrier and rarely did after day one. Exposed bumblebees were probably slower to use the successful strategy because they were behaviourally rigid; they switched between behaviours at a lower rate than did unexposed bumblebees - particularly during day one - and were more likely to persist using one strategy for long periods. Past work has shown that naïve bumblebees make frequent errors foraging on novel flowers but quickly improve through trial and error (Laverty, 1980), learning associatively which behavioural strategies result in successful manipulation of flowers and subsequent reward. It seems reasonable, therefore, that a delayed process of trial and error limited opportunities for associative learning and delayed acquisition of the successful strategy. Reduced exploration demonstrated here is consistent with past work by Phelps and colleagues (2018), which showed that imidacloprid-exposed bumblebees were slower to learn which flowers are rewarding because of reduced flower sampling. These results are also consistent with work on problem solving more generally, which has demonstrated the importance of exploration in problem solving across a range of species and tasks (Auersperg et al., 2012; Benson-Amram \& Holekamp, 2012; Thornton \& Samson, 2012).

Why did imidacloprid-exposed bumblebees show a reduction in behaviour switching but not in overall activity? While perhaps initially surprising, this result is consistent with previous findings. Williamson and colleagues (2014) found that honeybees exposed to thiamethoxam at field-realistic doses were not less active, but that they suffered coordination deficits such as 
impaired performance of the righting reflex. Similarly, Whitehorn and colleagues (2017) showed that thiamethoxam-exposed bumblebees could not fine-tune buzz pollination to maximize pollen collection. While neonicotinoids at sufficiently high doses unsurprisingly cause major activity reduction and paralysis (Godfray et al., 2015; Moffat et al., 2016; Switzer \& Combes, 2016; Williamson et al., 2014), effects at field-realistic levels are more subtle. The distribution of neonicotinoid-sensitive receptors in crucial motor control areas of the bee nervous system (e.g. the neuromuscular junctions and the ganglia of the ventral nerve cord) is less well understood than the distribution in learning and memory areas (e.g. the mushroom bodies and antennal lobes; Barbara et al., 2008; Deglise et al., 2002; Palmer et al., 2013). It was recently found, however, that honeybees exposed to imidacloprid at $10 \mathrm{ppb}$ showed significant down-regulation of muscle-related genes (Wu et al., 2017). This down-regulation, in addition to the blockage of nAChRs, may underlie the subtle motor deficits observed here and elsewhere.

While subtle imidacloprid-induced motor deficits were probably responsible for reduced behaviour switching, they may have acted in concert with associative learning deficits to cause delayed use of the successful motor strategy in bumblebees exposed at $10 \mathrm{ppb}$. Many studies have shown associative learning deficits in bees exposed to neonicotinoids at sub-lethal levels (Decourtye et al., 2004a; Decourtye et al., 2004b; Han et al., 2010; Phelps et al., 2018; Stanley et al., 2015a; Williamson and Wright 2013). Exposed bees often require more learning trials to form associations between stimuli. It may be the case, therefore, that exposed bumblebees not only gained experience with the successful motor strategy at a lower rate, but that they also required more experience using the strategy to form a strong association between it and the reward. More severe associative learning deficits in bumblebees exposed at $10 \mathrm{ppb}$ than those exposed at $2.6 \mathrm{ppb}$ may explain performance differences between these groups.

Inter-trial interval on day one was longer for bumblebees exposed at $10 \mathrm{ppb}$ than for unexposed bumblebees and those exposed at $2.6 \mathrm{ppb}$. This is partially because bumblebees exposed at $10 \mathrm{ppb}$ spent longer engaging in the task on day one. However, it may also be that they took longer to deposit sucrose and prepare for subsequent foraging trips. Importantly, this effect on day one was variable: inter-trial interval was only longer for bumblebees exposed at 10 ppb following trial one and between trials 6 and 10. Given this inconsistency, it is inappropriate to make claims about whether imidacloprid affects foraging rate. The relation between inter-trial interval and task performance was also variable: while inter-trial interval duration and latency to 
remove the rewarded barrier were positively correlated overall, the effect was largely driven by bumblebees exposed at $2.6 \mathrm{ppb}$. It is unclear whether bumblebees with longer inter-trial intervals were slower to solve the task due to increased forgetting, or whether these bumblebees were less motivated. While longer inter-trial intervals during day one in bumblebees exposed at $10 \mathrm{ppb}$ overall may have contributed to delayed improvement on the task, there was no relation between performance and inter-trial interval among bumblebees exposed at $10 \mathrm{ppb}$.

Bumblebees were of similar size across conditions and task performance did not vary as a function of body size. This finding conflicts with past work showing that larger bumblebees are typically faster to learn across contexts (Laverty, 1994a; Stanley et al., 2015a; Worden et al., 2009) and that memory in larger bees is more severely affected by neonicotinoid exposure (Samuelson et al., 2016; but see Stanley et al., 2015a). Bumblebees ranged widely in thorax width (3.62 to $5.41 \mathrm{~mm})$ so it is interesting that there were no size-related differences.

Since bumblebees were exposed chronically to imidacloprid in a free-flight scenario it was not possible to precisely manipulate how long bumblebees were exposed prior to testing. Colonies were, however, exposed for at least one week. A post-hoc analysis of time colonies were exposed prior to testing shows that treatment duration was similar for bumblebees across conditions. There was no relation between exposure duration and performance. Most bumblebees were tested within weeks two and three of exposure. While it is possible that some bumblebees were exposed to imidacloprid during development, this did not manifest in worse performance. The exact age of bumblebees was not known, however, so it is not possible to speculate about differential effects of imidacloprid during development and across the life span.

Bumblebee colonies often differ in the degree to which they are affected by pesticides (Phelps et al., 2018; Whitehorn et al., 2017). While bumblebees from colonies exposed at 0 and $10 \mathrm{ppb}$ performed similarly across replicates, bumblebees from one colony exposed at $2.6 \mathrm{ppb}$ performed significantly worse than those from the other two. Differences between bumblebees exposed at 0 and $2.6 \mathrm{ppb}$ appear largely driven by the poor performance of bumblebees from this colony and should thus be interpreted with caution. Consistent performance in colonies exposed at 0 and $10 \mathrm{ppb}$, however, does point to a robust effect of imidacloprid on motor learning at the level of $10 \mathrm{ppb}$. The colony variation problem is sometimes avoided by removing bumblebees from a single colony and testing them at each exposure level. Removing bumblebees from a natural colony context, however, reduces ecological validity and is not possible in studies of 
chronic pesticide exposure where bumblebees must return to the colony to deposit sucrose between trials.

Consistent motor learning delays in bumblebees exposed to imidacloprid at $10 \mathrm{ppb}$ may help explain why neonicotinoid exposure limits colony growth (Rundlöf et al., 2015; Whitehorn et al., 2012; Woodcock et al., 2017). Pollen is the key bumblebee protein resource and it is often found that neonicotinoid-exposed bumblebees collect less of it in the field (Feltham et al., 2014; Gill et al., 2012; Gill \& Raine, 2014; Stanley et al., 2016). Bumblebees must learn to handle flowers to collect pollen, and it therefore follows that neonicotinoid-induced motor learning delays may cause reduced pollen collection. Pollen foraging in bumblebees involves much more, however, than learning to handle flowers. Bumblebees must navigate to forage on a variety of flowers that differ not only in morphology but also in location, colour, scent and reward (Lawson et al., 2018; Muth et al., 2016; Nicholls \& Hempel de Ibarra, 2014; Thomson, 1996). Recent work has shown that neonicotioids also impair learning of both colour- and scent-reward associations (Phelps et al., 2018; Stanley et al., 2015a) and spatial memory (Samuelson et al., 2016). These effects are likely interacting to cause deficits in pollen foraging and, subsequently, reductions in reproductive success.

The model used here was designed to resemble handling of morphologically complex flowers. However, many flowers important to bees are morphologically simple and thus easier to handle (Laverty, 1980, 1994a; Strang, 2018). It would be valuable to test whether neonicotinoid exposure affects handling of morphologically simple flowers. It may be the case that exposed bumblebees can learn to handle simple flowers as effectively as unexposed bees but that subtle motor deficits reduce the efficiency with which they execute the motor pattern over the tens to hundreds of flower visits comprising a typical foraging bout in the wild (Brunet, 2009; Raine \& Chittka, 2007). Importantly, individuals often visit more than one flower species during foraging bouts (Chittka et al., 1997; Heinrich, 1979) and must learn several associations between floral features and reward value simultaneously (Muth et al., 2015). Bumblebees switch between handling flower species with an impressively low interference cost (Laverty, 1994b; Strang, 2018; Woodward \& Laverty, 1992). It would be valuable to test whether neonicotinoid exposure exacerbates memory interference in bumblebees learning to handle multiple flowers.

In summary, imidacloprid exposure caused a dose-dependent delay in bumblebee motor learning. Reduced performance in exposed bumblebees resulted from delayed use of the 
successful motor strategy, which itself may have resulted from reduced behaviour switching and impaired associative learning during early trials. This effect occurred consistently in colonies exposed at $10 \mathrm{ppb}$. At $2.6 \mathrm{ppb}$, however, the effect seems largely driven by bumblebees from one disproportionately affected colony. Results suggest, therefore, that imidacloprid exposure at 10 ppb causes clear deficits in motor learning but that exposure at lower doses in the field-realistic range may have variable effects across individuals. It is crucial that bumblebees learn to handle flowers to efficiently collect pollen. These results may help explain why bumblebees exposed to neonicotinoids collect less pollen while foraging in the field. 


\section{References}

Aizen, M. A., Harder, L. D. (2009). The global stock of domesticated honey bees is growing slower than agricultural demand for pollination. Current Biology, 19, 915-918.

Alford, D. V. (1975). Bumblebees. London, England: Davis-Poynter.

Auersperg, A. M. I., von Bayern, A. M. P., Gajdon, G. K., Huber, L., Kacelnik, A. (2012).

Flexibility in problem solving and tool use of Kea and New Caledonian Crows in a multi access box paradigm. PLoS One, 6, e20231.

Barbara, G. S., Grünewald, B., Paute. S., Gauthier, M., Raymond-Delpech, V. (2008). Study of nicotinic acetylcholine receptors on cultured antennal lobe neurones from adult honeybee brains. Invertebrate Neuroscience, 8, 19-29.

Baron, G. L., Jansen, V. A. A., Brown, M. J. F., Raine, N. E. (2017a). Pesticide reduces bumblebee colony initiation and increases probability of population extinction. Nature Ecology \& Evolution, 1, 1308-1316.

Baron, G. L., Raine, N. E., Brown, M. J. F. (2017b). General and species-specific impacts of a neonicotinoid insecticide on the ovary development and feeding of wild bumblebee queens. Proceedings of the Royal Society B: Biological Sciences, 284, 20170123.

Batra, S. W. T. (1995). Bees and pollination in our changing environment. Apidologie, 26, 361370.

Benson-Amram, S., Holekamp, K. E. (2012). Innovative problem solving by wild spotted hyenas. Proceedings of the Royal Society B: Biological Sciences, 279, 4087-4095.

Biesmeijer, J. C., Roberts, P. M., Reemer, M., Ohlemüller, R., Edwards, M., Peeters, T.,...Kunin, W. E. (2006). Parallel declines in pollinators and insect-pollinated plants in Britain and the Netherlands. Science, 313, 351-354.

Blacquière, T., Smagghe, G., van Gestel, C. A., Mommaerts, V. (2012). Neonicotinoids in bees: a review on concentrations, side-effects and risk assessment. Ecotoxicology, 21, 973-992.

Bonmatin, J. M., Giori, C., Girolami, V., Goulson, D., Kreutzweiser, D. P., Krupke, C.,...Tapparo, A. (2015). Environmental fate and exposure; neonicotinoids and fipronil. Environmental Science and Pollution Research, 22, 35-67.

Bortolotti, L., Sabatini, A. G., Mutinelli, F., Astuti, M., Lavazza, A., Piro, R.,...Porrini, C. (2009). Spring honey bee losses in Italy. Julius-Kühn-Arch, 423, 148-152. 
Botías, C., David, A., Horwood, J., Abdul-Sada, A., Nicholls, E., Hill, E., Goulson, D. (2015). Neonicotinoid residues in wildflowers, a potential route of chronic exposure for bees. Environmental Science and Technology, 49, 12731-12740.

Brown, M. J. F., Paxton, R. J. (2009). The conservation of bees: a global perspective. Apidologie, 40, 410-416.

Brunet, J. (2009). Pollinators of the Rocky Mountain Columbine: temporal variation, functional groups and associations with floral traits. Annals of Botany, 103, 1567-1578.

Calderone, N. W. (2012). Insect pollinated crops, insect pollinators and US agriculture: trend analysis of aggregate data for the period 1992-2009. PLoS One, 7, e37235.

Cameron, S. A., Lozier, J. D., Strange, J. P., Koch, J. B., Cordes, N., Solter, L. F., Griswold, T. L. (2011). Patterns of widespread decline in North American bumble bees. Proceedings of the National Academy of Sciences, 108, 662-667.

Chauzat, M-P., Martel, A-C., Blanchard, P., Clément, M-C., Schurr, F., Lair, C.,...Faucon, J-P. (2010). A case report of a honey bee colony poisoning incident in France. Journal of Apicultural Research, 49, 113-115.

Chittka, L. (1998). Sensorimotor learning in bumblebees: long-term retention and reversal training. Journal of Experimental Biology, 201, 515-524.

Chittka, L., Gumbert, A., Kunze, J. (1997). Foraging dynamics of bumble bees: correlates of movements within and between plant species. Behavioral Ecology, 8, 239-249.

Colla, S. R., Packer, L. (2008). Evidence for decline in eastern North American bumblebees (Hymenoptera: Apidae), with species focus on Bombus affinis Cresson. Biodiversity and Conservation, 17, 1379-1391.

Corbet, S. A., Williams, I. H., Osborne, J. L. (1991). Bees and pollination of crops and wild flowers in the European community. Bee World, 72, 47-59.

Corbet, S. A., Fussell, M., Ake, R., Fraser, A., Gunson, C., Savage, A., Smith, K. (1993). Temperature and the pollinating activity of social bees. Ecological Entomology, 18, 1730.

Cresswell, J. E. (2011). A meta-analysis of experiments testing the effects of a neonicotinoid insecticide (imidacloprid) on honey bees. Ecotoxicology, 20, 149-157. 
Cumber, R. A. (1953). Some aspects of the biology and ecology of bumble-bees bearing upon the yields of red-clover seed in New Zealand. New Zealand Journal of Science and Technology, 11, 227-240.

Dainat, B., Evans, J. D., Chen, Y. P., Gauthier, L., Neumann, P. (2012). Predictive markers of honey bee colony collapse. PLoS One, 7, e32151.

Dams, M., Dams, L. R. (1977). Spanish art rock depicting honey bee gathering during the Mesolithic. Nature, 268, 228-230.

Danforth, B. N., Cardinal, S., Praz, C., Almeida, E. A. B., Michez, D. (2013). Annual Review of Entomology, 58, 57-78.

David, A., Botías, C., Abdul-Sada, A., Nicholls, E., Rotheray, E. L., Hill, E. M., Goulson, D. (2016). Widespread contamination of wildflower and bee-collected pollen with complex mixtures of neonicotinoids and fungicides commonly applied to crops. Environment International, 88, 169-178.

De la Rúa, P., Jaffé, R., Dall'Olio, R., Muñoz, I., Serrano, J. (2009). Biodiversity, conservation and current threats to European honeybees. Apidologie, 40, 263-284.

Decourtye, A., Armengaud, C., Renou, M., Devillers, J., Cluzeau, S. Gauthier, M., PhamDelègue, M-H. (2004a). Imidacloprid impairs memory and brain metabolism in the honeybee (Apis mellifera L.). Pesticide Biochemistry and Physiology, 78, 83-92.

Decourtye, A., Devillers, J., Cluzeau, S., Charreton, M., Pham-Delègue, M-H. (2004b). Effects of imidacloprid and deltamethrin on associative learning in honeybees under semi-field and laboratory conditions. Ecotoxicology and Environmental Safety, 57, 410-419.

Deglise, P., Grünewald, B., Gauthier, M. (2002). The insecticide imidacloprid is a partial agonist of the nicotinic receptor of honey bee kenyon cells. Neuroscience Letters, 321, 13-16.

Delaplane, K. S., Mayer, D. F. (2000). Crop Pollination by Bees. Wallingford, England: CABI Publishing

Doublet, V., Labarussias, M., Miranda, J. R., Moritz, R. F. A., Paxton, R. J., Sveriges, I. (2015). Bees under stress: sublethal doses of a neonicotinoid pesticide and pathogens interact to elevate honey bee mortality across the life cycle. Environmental Microbiology, 17, 969983.

Doyle, J. A. (2012). Molecular and fossil evidence on the origin of angiosperms. Annual Review of Earth and Planetary Sciences, 40, 301-326. 
Duchateau, M. J., Velthuis, H. H. W. (1988). Development and reproductive strategies in Bombus terrestris colonies. Behaviour, 107, 186-207.

Dukas, R., Real, L. A. (1991). Learning foraging tasks by bees: a comparison between social and solitary species. Animal Behaviour, 42, 269-276.

Elbert, A., Haas, M., Springer, B., Thielert, W., Nauen, R. (2008). Applied aspects of neonicotinoid uses in crop protection. Pest Management Science, 64, 1099-1105.

European Food Safety Authority. (2013a). Conclusion on the peer review of the pesticide risk assessment for bees for the active substance imidacloprid. European Food Safety Authority Journal, 11, 3068.

European Food Safety Authority. (2013b). Conclusion on the peer review of the pesticide risk assessment for bees for the active substance thiamethoxam. European Food Safety Authority Journal, 11, 3067.

European Food Safety Authority. (2013c). Conclusion on the peer review of the pesticide risk assessment for bees for the active substance clothianidin. European Food Safety Authority Journal, 11, 3066.

Evans, L. J., Smith, K. E., Raine, N. E. (2017). Fast learning in free-foraging bumble bees is negatively correlated with lifetime resource collection. Scientific Reports, 7, 496.

Feltham, H., Park, K., Goulson, D. (2014). Field realistic doses of pesticide imidacloprid reduce bumblebee pollen foraging efficiency. Ecotoxicology, 23, 317-323.

Forup, M. L., Henson, K. S. E., Craze, P. G., Memmott, J. (2008). The restoration of ecological interactions: plant-pollinator networks on ancient and restored heathlands. Journal of Applied Ecology, 45, 742-752.

Gallai N., Salles, J-M., Settele, J., Vaissière, B. E. (2009). Economic valuation of the vulnerability of world agriculture confronted with pollinator decline. Ecological Economics, 68, 810-821.

Garibaldi, L. A., Steffan-Dewenter, I., Winfree, R., Aizen, M. A., Bommarco, R., Cunningham, S. A.,...Klein, A. M. (2013). Wild pollinators enhance fruit set of crops regardless of honey bee adbundance. Science, 340, 1608-1611.

Gill, R. J., Ramos-Rodriquez, O., Raine, N. E. (2012). Combined pesticide exposure severely affects individual- and colony-level traits in bees. Nature, 491, 105-108. 
Gill, R. J., Raine, N. E. (2014). Chronic impairment of bumblebee natural foraging behaviour induced by sublethal pesticide exposure. Functional Ecology, 28, 1459-1471.

Girolami, V., Marzaro, M., Vivan, L., Mazzon, L., Greatti, M., Giorio, C.,...Tapparo, A. (2012). Fatal powdering of bees in flight with particulates of neonicotinoid seed coating and humidity implication. Journal of Applied Entomology, 136, 17-26.

Girolami, V., Marzaro, M., Vivan, L., Mazzon L., Giorio, C., Marton, D., Tapparo, A. (2013). Aerial powdering of bees inside mobile cages and the extent of neonicotinoid cloud surrounding drillers. Journal of Applied Entomology, 137, 35-44.

Godfray, H. C. J., Blacquière, T., Field, L. M., Hails, R. S., Potts, S. G., Raine, N. E.,...McLean, A. R. (2015). A restatement of recent advances in the natural science evidence base concerning neonicotinoid insecticides and insect pollinators. Proceedings of the Royal Society B: Biological Sciences, 282, 20151821.

Goulson, D., Hughes, W. O. H., Derwent., L. C., Stout, J. C. (2002). Colony growth of the bumblebee, Bombus terrestris, in improved and conventional agricultural and suburban habitats. Oecologia, 130, 267-273.

Goulson, D. (2009). Bumblebees: behaviour, ecology and conservation (2nd ed.). Oxford, England: Oxford University Press.

Goulson, D., Lye, G. C., Darvill, B. (2008). Decline and conservation of bumble bees. Annual Review of Entomology, 53, 191-208.

Goulson, D. (2013). An overview of the environmental risks posed by neonicotinoid insecticides. Journal of Applied Ecology, 50, 977-987.

Graystock, P. Goulson, D., Hughes, W. O. H. (2014). The relationship between managed bees and the prevalance of parasites in bumblebees. PeerJ, 2, e522.

Grimaldi, D. (1999). The co-radiations of pollinating insects and angiosperms in the cretaceous. Annals of the Missouri Botanical Garden, 86, 373-406.

Grixti, J. C., Wong, L. T., Cameron, S. A., Favret, C. (2009). Decline of bumble bees (Bombus) in the North American Midwest. Biological Conservation, 142, 75-84.

Hallman, C. A., Sorg, M., Jongejans, E., Siepel, H., Hofland, N., Schwan, H.,...de Kroon, H. (2017). More than 75 percent decline over 27 years in total flying insect biomass in protected areas. PLoS One, 12, e0185809. 
Han, P., Niu, C-Y., Lei, C-L., Cui, J-J., Desneux, N. (2010). Use of an innovative T-tube maze assay and the proboscis extension response assay to assess sublethal effects of GM products and pesticides on learning capacity of the honey bee Apis mellifera L. Ecotoxicology, 19, 1612-1619.

Heinrich, B. (1976). The foraging specializations of individual bumblebees. Ecological Monographs, 46, 105-128.

Heinrich, B. (1979). “Majoring” and “minoring” by foraging bumblebees, Bombus vagans: an experimental analysis. Ecology, 60, 245-255.

Heinrich, B. (2004). Bumblebee Economics (Revised Edition). Cambridge, MA: Harvard University Press.

Henry, M., Béguin, M., Requier, F., Rollin, O., Odoux, J-F., Aupinel, P.,...Decourtye, A. (2012). A common pesticide decreases foraging success and survival in honey bees. Science, 336 , 348-350.

Holzschuh, A., Steffan-Dewenter, I., Tscharntke, T. (2008). Agricultural landscapes with organic crops support higher pollinator diversity. Oikos, 117, 354-361.

Horth, L., Campbell, L. A. (2018). Supplementing small farms with native mason bees increases strawberry size and growth rate. Journal of Applied Ecology, 55, 591-599.

Hu, S., Dilcher, D. L., Jarzen, D. M., Taylor, D, W. (2008). Early steps of angiosperm-pollinator coevolution. Proceedings of the National Academy of Sciences, 105, 240-245.

Hung, K. J., Kingston, J. M., Albrecht, M., Holway, D. A., Kohn, J. R. (2018). The worldwide importance of honey bees as pollinators in natural habitats. Proceedings of the Royal Society B: Biological Sciences, 285, 20172140.

Jacobson, M. M., Tucker, E. M., Mathiasson, M. E., Rehan, S. M. (2018). Decline of bumble bees in northeastern North America, with special focus on Bombus terricola. Biological Conservation, 217, 437-445.

Jaffé, R., Dietemann, V., Allsopp, M. H., Costa, C., Crewe, R. M., Dall’Olio, R.,...Moritz, R. F. A. (2010). Estimating the density of honeybee colonies across their natural range to fill the gap in pollinator decline censuses. Conservation Biology, 24, 583-593.

Jeschke, P., Nauen, R., Schindler, M., Elbert, A. (2011). Overview of the status and global strategy for neonicotinoids. Journal of Agricultural and Food Chemistry, 59, 2897-2908. 
Kerr, J. T., Pindar, A., Galpern, P., Packer, L., Potts, S. G., Roberts, S.,...Pantoja, A. (2015). Climate change impacts on bumblebees converge across continents. Science, 349, 177180.

Klein, A., Vaissière, B. E., Cane, J. H., Steffan-Dewenter, I., Cunningham, S., Kremen, C., Tscharntke, T. (2007). Importance of pollinators in changing landscapes for world crops. Proceedings of the Royal Society B: Biological Sciences, 274, 303-313.

Kremen, C., Williams, N. M., Aizen, M. A., Gemmill-Herrn, B., LeBuhn, G., Minckley, R.,...Ricketts, T. H. (2007). Pollination and other ecosystem services produced by mobile organisms: a conceptual framework for the effects of land-use change. Ecology Letters, 10, 299-314.

Kosior, A., Celary, W., Olejniczak, P., Fijal, J., Król, W., Solarz, W., Plonka, P. (2007). The decline of the bumble bees and cuckoo bees (Hymenoptera: Apidae: Bombini) of Western and Central Europe. Oryx, 41, 79-88.

Kulahci, I. G., Dornhaus, A., Papaj, D. R. (2008). Multimodal signals enhance decision making in foraging bumble-bees. Proceedings of the Royal Society B: Biological Sciences, 275, 797-802.

Laverty, T. M. (1980). The flower-visiting behaviour of bumble bees: floral complexity and learning. Canadian Journal of Zoology, 58, 1324-1335.

Laverty, T. M. (1994a). Bumble bee learning and flower morphology. Animal Behaviour, 47, 531-545.

Laverty, T. M. (1994b). Costs to foraging bumble bees of switching plant species. Canadian Journal of Zoology, 72, 43-47.

Laverty, T. M., Plowright, R. C. (1988). Flower handling by bumblebees: a comparison of specialists and generalists. Animal Behaviour, 36, 733-740.

Lawson, D. A., Chittka, L., Whitney, H. M., Rands, S. M. (2018). Bumblebees distinguish floral scent patterns, and can transfer these to corresponding visual patterns. Proceedings of the Royal Society B: Biological Sciences, 285, 20180661.

Laycock, I., Lenthall, K. M., Barratt., Cresswell, J. E. (2012). Effects of imidacloprid, a neonicotinoid pesticide, on reproduction in worker bumble bees (Bombus terrestris). Ecotoxicology, 21, 1937-1945. 
Long, E. Y., Krupke, C. H. (2016). Non-cultivated plants present a season-long route of pesticide exposure for honey bees. Nature Communications, 7, 11629.

Lunau, K. (1991). Innate recognition of flowers by bumble bees: orientation of antennae to visual stamen signals. Canadian Journal of Zoology, 70, 2139-2144.

Lundin, O., Rundlöf, M., Smith, H. G., Fries, I., Bommarco, R. (2015). Neonicotinoid insecticides and their impacts on bees: a systematic review of research approaches and identification of knowledge gaps. PLoS One, 10, e0136928.

Mallinger, R. E., Gratton, C. (2016). Species richness of wild bees, but not the use of managed honeybees, increases fruit set of a pollinator-dependent crop. Journal of Applied Ecology, 52, 323-330.

Mallinger, R. E., Gaines-Day, H. R., Gratton, C. (2017). Do managed bees have negative effects on wild bees?: A systematic review of the literature. PLoS One, 12, e0189268.

Manzone, M., Balsari, P., Marucco., P., Tamagnone, M. (2016). Potential external contamination of pneumatic seed drills during sowing of dressed maize seeds. Pest Management Science, $72,1302-1308$.

Matsuda, K., Buckingham, S. D., Kleier, D., Rauh, J. J., Grauso, M., Sattelle, D. B. (2001). Neonicotinoids: insecticides acting on insect nicotinic acetylcholine receptors. Trends in Pharmacological Sciences, 22, 573-580.

Matsumoto, T. (2013). Reduction in homing flights in the honey bee Apis mellifera after a sublethal dose of neonicotinoid insecticides. Bulletin of Insectology, 66, 1-9.

Michener, C. D. (2007). The Bees of the World (2nd ed.). Baltimore, MD: Johns Hopkins University Press.

Ministry of the Environment and Climate Change. (2015). Neonicotinoid Regulations. Retrieved from the Government of Ontario website: https://www.ontario.ca/page/neonicotinoidregulations.

Moffat, C., Buckland, S. T., Samson, A. J., McArthur, R., Chamosa Pino, V., Bollan, K. A.,...Connolly, C. N. (2016). Neonicotinoids target distinct nicotinic acetylcholine receptors and neurons, leading to differential risks to bumblebees. Scientific Reports, 6 , 24764. 
Morgan, T., Whitehorn, P., Lye, G. C., Vallejo-Marín, M. (2016). Floral sonication is an innate behaviour in bumblebees that can be fine-tuned with experience in manipulating flowers. Journal of Insect Behaviour, 29, 233-241.

Moritz, R. F. A., de Miranda, J., Fries, I., Le Conte, Y., Neumann, P., Paxton, R. J. (2010). Research strategies to improve honeybee health in Europe. Apidologie, 41, 227-242.

Morrissey, C. A., Mineau, P., Devries, J. H., Sánchez-Bayo, F., Liess, M., Cavallaro, M. C., Liber, K. (2015). Neonicotinoid contamination of global surfacewaters and associated risk to aquatic invertebrates: a review. Environment International, 74, 291-303.

Müller, C., Schmid-Hempel, P. (1992). Correlates of reproductive success among field colonies of Bombus lucorum: the importance of growth and parasites. Ecological Entomology, 17, 343-353.

Muth, F., Papaj, D, R., Leonard, A. S. (2015). Colour learning when foraging for nectar and pollen: bees learn two colours at once. Biology Letters, 11, 20150628.

Muth, F., Papaj, D. R., Leonard, A. S. (2016). Bees remember flowers for more than one reason: pollen mediates associative learning. Animal Behaviour, 111, 93-100.

National Research Council. (2007). Status of Pollinators in North America. Washington, DC: The National Academies Press.

Nicholls, E., Hempel de Ibarra, N. (2014). Bees associate colour cues with differences in pollen rewards. Journal of Experimental Biology, 217, 2783-2788.

Nuyttens, D., Devarrewaere, W., Verboven, P., Foqué D. (2013). Pesticide-laden dust emission and drift from treated seeds during seed drilling: a review. Pest Management Science, 69, 564-575.

Ollerton, J., Winfree, R., Tarrant, S. (2011). How many flowering plants are pollinated by animals? Oikos, 120, 321-326.

Otterstatter, M. C., Thomson, J. D. (2008). Does pathogen spillover from commercially reared bumble bees threaten wild pollinators? PLoS One, 3, e2771.

Otti, O., Schmid-Hempel, P. (2008). A field experiment on the effect of Nosema bombi in colonies of the bumblebee Bombus terrestris. Ecological Entomology, 33, 577-582.

Owen, R. E., Rodd, F. H., Plowright, R. C. (1980). Sex ratio in bumble bee colonies: complications due to orphaning? Behavioural Ecology and Sociobiology, 7, 287-291. 
Palmer, M. J., Moffat, C., Saranzewa, N., Harvey, J., Wright, G. A., Connolly, C. N. (2013). Cholinergic pesticides cause mushroom body neuronal inactivation in honeybees. Nature Communications, 4, 1634.

Peat, J., Goulson, D. (2005). Effects of experience and weather on foraging rate and pollen versus nectar collection in the bumblebee, Bombus terrestris. Behavioral Ecology and Sociobiology, 58, 152-156.

Pettis, J. S., vanEngelsdorp, D., Johnson, J., Dively, G. (2012). Pesticide exposure in honey bees results in increased levels of the gut pathogen Nosema. Naturwissenschaften, 99, 153158.

Phelps, J. D., Strang, C. G., Gbylik-Sikorska, M., Sniegocki, T., Andrzej, P., Sherry, D. F. (2018). Imidacloprid slows the development of preference for rewarding food sources in bumblebees (Bombus impatiens). Ecotoxicology, 27, 175-187.

Piiroinen, S., Goulson, D. (2016). Chronic neonicotinoid exposure and pesticide stress differentially affects learning in honeybees and bumblebees. Proceedings of the Royal Society B: Biological Sciences, 283, 20160246.

Piiroinen, S., Botías, C., Nicholls, E. (2016). No effect of low-level chronic neonicotinoid on bumblebee learning and fecundity. PeerJ, 4, e1808.

Plowright, R. C., Laverty, T. M. (1987). Bumble bees and crop pollination in Ontario. Proceedings of the Entomological Society of Ontario, 118, 155-160.

Potts, S. G., Biesmeijer, J. C., Kremen, C., Neumann, P., Schweiger, O., Kunin, W. E. (2010a). Global pollinator declines: trends, impacts and drivers. Trends in Ecology and Evolution, 25, 345-353.

Potts, S. G., Roberts, S. P. M., Dean, R., Marris, G., Brown, M. A., Jones, R., ...Settele, J. (2010b). Declines of managed honey bees and beekeepers in Europe. Journal of Apicultural Research, 49, 15-22.

Prisco, G. D., Cavaliere, V., Annoscia, D., Varricchio, P., Caprio, E., Nazzi, F.,...Pennacchio, F. (2013). Neonicotinoid clothianidin adversely affects insect immunity and promotes replication of viral pathogen in honey bees. Proceedings of the National Academy of Sciences, 110, 18466-18471. 
Rader, R., Bartomeus, I., Garibaldi, L. A., Garratt, M. P. D., Howlett, B. G., Winfree, R., ...Woyciechowski, M. (2016). Non-bee insects are important contributors to global crop pollination. Proceedings of the National Academy of Sciences, 113, 146-151.

Radolinski, J., Wu, J., Xia, K., Stewart, R. (2016). Transport of a neonicotinoid pesticide, thiamethoxam, from artificial seed coatings. Science of the Total Environment, 15, 561568.

Raine, N. E., Chittka, L. (2007). Pollen foraging: learning a complex motor skill by bumblebees (Bombus terrestris). Naturwissenschaften, 94, 459-464.

Raine, N. E., Chittka, L. (2008). The correlation of learning speed and natural foraging success in bumble-bees. Proceedings of the Royal Society B: Biological Sciences, 275, 803-808.

Richards, K. W. (1993). Non-Apis bees as crop pollinators. Revue Suisse De Zoologie, 4, 807822.

Richards, K. W. (2016). Effectiveness of the alfalfa leafcutter bee Megachile rotundata Fab. to pollinate perennial clovers. Journal of Apicultural Research, 55, 259-267.

Rick, C. M. (1950). Pollination relations of Lycopersicon esculentum in native and foreign regions. Evolution, 4, 110-122.

Ricketts, T. H., Regetz, J., Steffan-Dewenter, I., Cunningham, S. A., Kremen, C., Bogdanksi, A.,...Viana, B. F. (2008). Landscape effects on crop pollination services: are there general patterns? Ecology Letters, 11, 499-515.

Roffet-Salque, M., Regert, M., Evershed, R. P., Outram, A. K., Cramp, L. J. E., Decavallas, O.,...Zoughlami, J. (2015). Widespread exploitation of the honeybee by early Neolithic farmers. Nature, 527, 226-230.

Ronse De Craene, L. P. (2010). Floral diagrams: an aid to understanding flower morphology and evolution. Cambridge, England: Cambridge University Press.

Rundlöf, M., Andersson, G. K. S., Bommarco, R., Fries, I., Hederström, V., Herbertsson, L.,...Smith, H. G. (2015). Seed coating with a neonicotinoid insecticide negatively affects wild bees. Nature, 521, 77-80.

Samuelson, E. E. W., Chen-Wishart, Z. P., Gill, R. J., Leadbeater, E. (2016). Effect of acute pesticide exposure on bee spatial working memory using an analogue of the radial-arm maze. Scientific Reports, 6, 38957. 
Schnier, H. F., Wenig, G., Laubert, F., Simon, V., Schmuck, R. (2003). Honey bee safety of imidacloprid corn seed treatment. Bulletin of Insectology, 56, 73-75.

Scott-Dupree, C. D., Conroy, L., Harris, C. R. (2009). Impact of currently used or potentially useful insecticides for canola agroecosystems on Bombus impatiens (Hymenoptera: Apidae), Megachilidae rotunda (Hymenoptera: Megachilidae), and Osmia lignaria (Hymenoptera: Megachilidae). Journal of Economic Entomology, 102, 177-182.

Seeley, T. D. (2010). Honeybee Democracy. Princeton, NJ: Princeton University Press.

Şerban, P., Wilson, J. R. U., Vamosi, J. C., Richardson, D. M. (2008). Plant diversity in the human diet: weak phylogenetic signal indicates breadth. BioScience, 58, 151-159.

Sgolastra, F., Medrzycki, P., Bortolotti, L., Renzi, M. T., Tosi, S., Bogo, G.,...Bosch, J. (2016). Synergistic mortality between a neonicotinoid insecticide and an ergosterol-biosynthesisinhibiting fungicide in three bee species. Pest Management Science, 73, 1236-1243.

Smith, T. J., Saunders, M. E., Leather, S. R., Packer, L. (2016). Honey bees: the queens of the mass media, despite minority rule among insect pollinators. Insect Conservation and Diversity, 9, 384-390.

Soliman, M. M. M. (2012). Effects of UV-light, temperature and storage on the stability and biological effectiveness of some insecticides. Journal of Plant Protection Research, 52, 275-280.

Stanley, D. A., Smith, K. E., Raine, N. E. (2015a). Bumblebee learning and memory is impaired by chronic exposure to a neonicotinoid pesticide. Scientific Reports, 5, 16508.

Stanley, D. A., Garratt, M. P. D., Wickens, J. B., Wickens, V. J., Potts, S. G., Raine, N. E. (2015b). Neonicotinoid pesticide exposure impairs crop pollination services provided by bumblebees. Science, 528, 548-550.

Stanley, D. A., Raine, N. E. (2016). Chronic exposure to a neonicotinoid pesticide alters the interactions between bumblebees and wild plants. Functional Ecology, 30, 1132-1139.

Stanley, D. A., Russell, A. L., Morrison, S. J., Rogers, C., Raine, N. E. (2016). Investigating the impacts of field-realistic exposure to a neonicotinoid pesticide on bumblebee foraging, homing ability and colony growth. Journal of Applied Ecology, 53, 1440-1449.

Stanley, D. A., Raine, N. E. (2017). Bumblebee colony development following chronic exposure to field-realistic levels of the neonicotinoid pesticide thiamethoxam under laboratory conditions. Scientific Reports, 7, 8005. 
Strang, C. (2018). Behavioural flexibility in bumblebees (Bombus impatiens). Electronic Thesis and Dissertation Repository, 5322. https://ir.lib.uwo.ca/etd/5322.

Stoner, K. (2016). Current pesticide risk assessment protocols do not adequately address differences between honey bees (Apis mellifera) and bumble bees (Bombus spp.). Frontiers in Environmental Science, 4, 79.

Sur, R., Stork., A. (2003). Uptake, translocation and metabolism of imidacloprid in plants. Bulletin of Insectology, 56, 35-40.

Switzer, C. M., Combes, S. A. (2016). The neonicotinoid pesticide, imidacloprid, affects Bombus impatiens (bumblebee) sonication behavior when consumed at doses below the LD50. Ecotoxicology, 25, 1150-1159.

Thomson, J. (1996). Trapline foraging by bumblebees: I. Persistence of flight-path geometry. Behavioral Ecology, 7, 158-164.

Thornton, A., Samson, J. (2012). Innovative problem solving in wild meerkats. Animal Behaviour, 83, 1459-1468.

Tomizawa, M., Casida, J. E. (2005). Neonicotinoid insecticide toxicology: mechanisms of selective action. Annual Review of Pharmacology and Toxicology, 45, 247-268.

Tosi, S., Demares, F. J., Nicolson, S. W., Medrzycki, P., Pirk, C. W. W., Human, H. (2016). Effects of a neonicotinoid pesticide on thermoregulation of African honey bees (Apis mellifera scutellata). Journal of Insect Physiology, 93, 56-63.

Vergara, C. H., Fonseca-Buendía, P. (2012). Pollination of greenhouse tomatoes by the Mexican bumblebee Bombus ephippiatus (Hymenoptera: Apidae). Journal of Pollination Ecology, 7, 27-30.

Vogt, F. D., Heinrich, B., Plowright, C. (1998). Ovary development in bumble bee queens: the influence of abdominal temperature and food availability. Canadian Journal of Zoology, 76, 2026-2030.

von Frisch, K. (1967). The Dance Language and Orientation of Bees. Cambridge, MA: Harvard University Press.

Waser, N. M., Chittka, L., Price, M. V., Williams, N. M., Ollerton, J. (1996). Generalization in pollination systems, and why it matters. Ecology, 77, 1043-1060.

Westerkamp, C. (1991). Honeybees are poor pollinators - why? Plant Systematics and Evolution, 177, 71-75. 
Whitehorn, P. R., O'Connor, S., Wackers, F. L., Goulson, D. (2012). Neonicotinoid pesticide reduces bumble bee colony growth and queen production. Science, 336, 351-352.

Whitehorn, P. R., Wallace, C., Vallejo-Marin, M. (2017). Neonicotinoid pesticide limits improvement in buzz pollination by bumblebees. Scientific Reports, 7, 15562.

Williams, P. H., Osborne, J. L. (2009). Bumblebee vulnerability and conservation world-wide. Apidologie, 40, 367-387.

Williamson, S. M., Wright, G. A. (2013). Exposure to multiple cholinergic pesticides impairs olfactory learning and memory in honeybees. Journal of Experimental Biology, 216, 1799-1807.

Williamson, S. M., Willis, S. J., Wright, G. A. (2014). Exposure to neonicotinoids influences the motor function of adult worker honeybees. Ecotoxicology, 23, 1409-1418.

Willmer, P. (2011). Pollination and Floral Ecology. Princeton, NJ: Princeton University Press.

Winfree, R., Williams, N. M., Gaines, H., Ascher, J. S., Kremen, C. (2008). Wild bee pollinators provide the majority of crop visitations across land-use gradients in New Jersey and Pennsylvania, USA. Journal of Applied Ecology, 45, 793-802.

Winfree, R., Aguilar, R., Vázquez, D. P., LeBuhn, G., Aizen, M. A. (2009). A meta-analysis of bees' responses to anthropogenic disturbance. Ecology, 90, 2068-2076.

Wood, T. J., Goulson, D. (2017). The environmental risks of neonicotinoid pesticides: a review of evidence post 2013. Environmental Science and Pollution Research, 24, 17285-17325.

Woodcock, B. A., Bullock, J. M., Shore, R. F., Heard, M. S., Pereira, M. G., Redhead, J.,...Pywell, R. F. (2017). Country-specific effects of neonicotinoid pesticides on honey bees and wild bees. Science, 356, 1393-1395.

Woodward, G. L., Laverty, T. M. (1992). Recall of flower handling skills by bumble bees: A test of Darwin's interference hypothesis. Animal Behaviour, 44, 1045-1051.

Worden, B. D., Skemp, A. K., Papaj, D. R. (2009). Learning in two contexts: the effects of interference and body size in bumblebees. Journal of Experimental Biology, 208, 20452053.

Wu, Y-Y., Luo, Q-H., Hou, C-S., Wang, Q., Dai, P-L., Gao, J.,...Diao, Q-Y. (2017). Sublethal effects of imidacloprid on targeting muscle and ribosomal protein related genes in the honey bee Apis mellifera L. Scientific Reports, 7, 15943. 
Wu-Smart, J., Spivak, M. (2018). Effects of neonicotinoid imidacloprid exposure on bumble bee (Hymenoptera: Apidae) queen survival and nest initiation. Pollinator Ecology and Management, 47, 55-62.

Zayed, A. (2009). Bee genetics and conservation. Apidologie, 40, 237-262. 


\title{
CURRICULUM VITAE \\ Jordan Phelps
}

\author{
June 2018
}

Department of Psychology

Western University

London, ON, N6A 5C2

\section{Academic History}

- MSc, Psychology: Behavioural \& Cognitive Neuroscience, Western University, Exp. 2018. Thesis advisor: Dr. David Sherry

- B.A., Psychology (with honours), Western University, 2016. Thesis advisor: Dr. David Sherry

\section{Honours and Awards}

- Ontario Graduate Scholarship. Western University, 2018.

- The W. J. McClelland Award (awarded for the outstanding senior thesis in the honours psychology class 2015-2016). Western University, 2016.

- Canadian Psychological Association's Certificate of Academic Excellence (Undergraduate). Western University, 2016.

- Dean's Honor List. Western University, 2013-2016.

- NSERC Undergraduate Student Research Award. Western University, 2016.

- Continuing Scholarship. King's University College, 2013.

- Entrance Scholarship. King's University College, 2012.

\section{Publications}

- Phelps JD, Strang CG, Gbylik-Sikorska M, Sniegocki T, Posyniak A, Sherry DF. (2018). Imidacloprid slows the development of preference for rewarding food sources in bumblebees (Bombus impatiens). Ecotoxicology, 27, 175-187.

\section{Conference Presentations}

- Phelps JD. (2018) Using a novel motor task to assess sub-lethal effects of imidacloprid exposure on complex motor learning in bumblebees (Bombus impatiens). 25 th International Conference on Comparative Cognition, Melbourne, Florida, USA (April 2018).

- Phelps JD. (2017) Using a novel motor task to assess sub-lethal effects of imidacloprid exposure on complex motor learning in bumblebees (Bombus impatiens). Building Our Methods Using Sound Science (BOMBUSS), Utah State University, Logan, Utah, USA (August 2017).

- Phelps JD. (2017) Imidacloprid slows the development of preference for rewarding food sources in bumblebees (Bombus impatiens). 24 ${ }^{\text {th }}$ International Conference on Comparative Cognition, Melbourne, Florida, USA (April 2017). 


\section{Research Experience}

MSc Research

- Assessment of the effect of a neonicotinoid pesticide, imidacloprid, on motor learning in bumblebees (Bombus impatiens) using a novel task that models flowers handling.

Undergraduate Thesis Research

- Assessment of the effect of a neonicotinoid pesticide, imidacloprid, on learning of colourreward associations in free-flying bumblebees (Bombus impatiens)

Undergraduate Volunteer and NSERC USRA Research

- Investigating motor learning and memory in bumblebees (Bombus impatiens) using a novel task that models flower handling.

- Assessment of the effect of memantine on behavioural flexibility in black-capped chickadees (Poecile atricapillus).

\section{Service and Professional Affiliations}

- Ad hoc reviewer: Ecotoxicology

- Student Member of the Comparative Cognition Society (2017-2018)

\section{Teaching Experience}

- Graduate Teaching Assistant. Evolutionary Psychology: The Science of Human Nature (3228), Western University, 2017.

- Graduate Teaching Assistant. Research Methods in Psychology (2800), Western University, 2016-2017.

\section{Guest Lectures}

- Phelps, JD. (March 2017). How are neonicotinoids affecting bumblebees? Guest lecture - Psychology 2855: Research Methods in Psychology, Brescia University College.

\section{Volunteer Experience}

- Bug Day, London Children's Museum (September 2016 and 2017) - I introduced visitors to a bumblebee colony and discussed bee psychology and biology. 